\title{
Drought response of cowpea (Vigna unguiculata (L.) Walp.) landraces at leaf physiological and metabolite profile levels
}

\author{
Ana M.F. Gomes ${ }^{\mathrm{a}, \mathrm{b}, \mathrm{c}}$, Ana P. Rodrigues ${ }^{\mathrm{d}}$, Carla António ${ }^{\mathrm{e}}$, Ana M. Rodrigues ${ }^{\mathrm{e}}$, António E. Leitão ${ }^{\mathrm{a}, \mathrm{f}}$, \\ Paula Batista-Santos $^{\mathrm{a}}$, Nascimento Nhantumbo ${ }^{\mathrm{b}}$, Rafael Massinga ${ }^{\mathrm{b}}$, Ana I. Ribeiro-Barros ${ }^{\mathrm{a}, \mathrm{d}, *}$, \\ José C. Ramalho ${ }^{\mathrm{a}, \mathrm{f}, *}$ \\ ${ }^{a}$ Plant-Environment Interactions \& Biodiversity Lab (PlantStress\&Biodiversity), Linking Landscape, Environment, Agriculture and Food (LEAF), Instituto Superio de \\ Agronomia (ISA), Universidade de Lisboa (UL), Oeiras, Lisbon, Portugal \\ ${ }^{\mathrm{b}}$ Divisão de Agricultura, Instituto Superior Politécnico de Manica (DivAG-ISPM), Manica, Mozambique \\ ${ }^{\mathrm{c}}$ TropiKMan Doctorate Programme, Nova School of Business and Economics, Universidade NOVA de Lisboa, Carcavelos, Portugal \\ ${ }^{\mathrm{d}}$ Forest Research Center (CEF), Instituto Superior de Agronomia (ISA), Universidade de Lisboa (UL), Lisbon, Portugal \\ ${ }^{\text {e }}$ Plant Metabolomics Laboratory, Instituto de Tecnologia Química e Biológica António Xavier (ITQB), Universidade NOVA de Lisboa (UNL), Oeiras, Portugal \\ ${ }^{\mathrm{f}}$ GeoBioSciences, GeoTechnologies and GeoEngineering (GeoBioTec), Faculdade de Ciências e Tecnologia (FCT), Universidade NOVA de Lisboa (UNL), Caparica, Portugal
}

\section{A R T I C L E I N F O}

\section{Keywords:}

Photoprotection

Photosynthesis

Primary metabolome

RuBisCO

Water deficit

\begin{abstract}
A B S T R A C T
Drought threatens the world's food production, particularly in Sub Saharan Africa low external input and rain fed agricultural systems, where cowpea (Vigna unguiculata (L.) Walp.) is an important food crop. In the context of growing concerns regarding climate changes implications on water availability, this study aimed at 1) to evaluate the drought responses in cowpea landraces with contrasting drought tolerance levels (A55 - high sensitivity; A80 - mild sensitivity; A116 - tolerant), 2) using an integrated physiological (leaf gas exchanges; chlorophyll $a$ fluorescence) and biochemical (photoprotective pigments; RuBisCO activity; primary metabolite profiling) analysis to identify drought tolerance probes, in plants submitted to three water availability levels (well-watered, WW; mild drought, MD; severe drought, SD). A116 plants maintained a better water status under drought, what could justify the higher $\mathrm{P}_{\mathrm{n}}$ and $\mathrm{P}_{\text {nmax }}$ values in MD, as well as higher photochemical use of energy (reflected in the photochemical quenching $\left(\mathrm{q}_{\mathrm{L}}\right)$ and in the quantum yield of non-cyclic electron transport $\left(\mathrm{Y}_{(\mathrm{II})}\right)$ ), and the lower need of photoprotective thermal dissipation mechanisms (given by the non-photochemical quenching $\left(\mathrm{q}_{\mathrm{N}}\right)$, and the quantum yield of regulated energy dissipation at photosystem PSII $\left(\mathrm{Y}_{(\mathrm{NPQ})}\right)$ ), in MD and SD plants. Greater declines of net $\left(\mathrm{P}_{\mathrm{n}}\right)$ and potential $\left(\mathrm{P}_{\mathrm{nmax}}\right)$ photosynthesis were observed in A55 plants, which frequently showed significant impacts already under MD conditions in most parameters, whereas A80 usually displayed and intermediate behaviour. Still, even A55 showed some acclimation response, regarding photoprotective mechanisms associated with high contents of zeaxanthin, lutein, and carotenes, and high $\mathrm{Y}_{(\mathrm{NPQ})}$, and $\mathrm{q}_{\mathrm{N}}$ values, supporting the absence of an increase in the non-regulated energy dissipation at PSII $\left(\mathrm{Y}_{(\mathrm{NO})}\right.$ did not increased) even in SD plants. Additionally, A55 was not significantly affected in RuBisCO activity, which showed to be quite resilient in cowpea. A primary metabolite profiling, complemented with a partial least square discrimination analysis (PLS-DA), allowed a better separation of A116 and A55 plants according to their degree of drought tolerance. In response to drought, A116 showed the greatest accumulation of most responsive metabolites, 14 in total, with sucrose, fucose, urea, alanine and putrescine being exclusively increased in this genotype, suggesting that they can be candidates as drought tolerance proxies. Other compounds, as proline, valine, isoleucine (among amino acids), and rhamnose and raffinose (among sugars) showed close increase patterns
\end{abstract}

\footnotetext{
Abbreviations: Chl, chlorophyll; $\mathrm{F}_{\mathrm{o}}$, minimum fluorescence; $\mathrm{F}_{\mathrm{s}} / \mathrm{F}_{\mathrm{m}}$ ', predictor of the rate constant of PSII inactivation; $\mathrm{F}_{\mathrm{v}} / \mathrm{F}_{\mathrm{m}}$ and $\mathrm{F}_{\mathrm{v}}{ }^{\prime} / \mathrm{F}_{\mathrm{m}}{ }^{\prime}$, maximal (dark) and actual (light) photochemical efficiency of PSII; GC-TOF-MS, gas chromatography time of flight mass spectrometry; $\mathrm{g}_{\mathrm{s}}$, stomatal conductance rate to water vapor; iWUE, instantaneous water use efficiency $\left(\mathrm{P}_{\mathrm{n}} / \mathrm{T}_{\mathrm{r}}\right)$; PCA, Principle Component Analysis; PLS-DA, Partial Least Squares Discriminant Analysis; $\mathrm{PI}_{\text {Dyn }}, \mathrm{PI}_{\text {Chr }}, \mathrm{PI}_{\text {Total }}$, dynamic, chronic and total PSIIphotoinhibition indexes; $\mathrm{P}_{\mathrm{n}}$, net photosynthetic rate; $\mathrm{P}_{\mathrm{nmax}}$, potential net photosynthetic rate (under $1500 \mu \mathrm{L} \mathrm{CO}_{2} \mathrm{~L}^{-1}$ ); PSII, photosystem II; $\mathrm{q}_{\mathrm{L}}$ and $\mathrm{q}_{\mathrm{N}}$, photochemical and non-photochemical quenchings; RuBisCO, ribulose-1,5-bisphosphate carboxylase/oxygenase; RWC, relative water content; $\mathrm{T}_{\mathrm{r}}$, transpiration rate; $\mathrm{Y}_{(\mathrm{II})}, \mathrm{Y}_{(\mathrm{NPQ})}, \mathrm{Y}_{(\mathrm{NO})}$, Estimates of the quantum yields of photosynthetic non-cyclic electron transport, of regulated energy dissipation of PSII, and of nonregulated energy dissipation of PSII

${ }^{*}$ Corresponding authors at: Plant-Environment Interactions \& Biodiversity Lab (PlantStress\&Biodiversity), Linking Landscape, Environment, Agriculture and Food (LEAF), Instituto Superior de Agronomia (ISA), Universidade de Lisboa (UL), Oeiras, Lisbon, Portugal.

E-mail addresses: aribeiro@isa.ulisboa.pt (A.I. Ribeiro-Barros), cochichor@mail.telepac.pt (J.C. Ramalho).
} 
across landraces, thus they would be involved in the common drought response of cowpea plants. This pioneer approach to characterize Africa's and Central Mozambique highly diverse cowpea germplasm, highlights the advantages of an integrated physiological and biochemical analysis, to identify response mechanisms and potential probes for drought tolerance in cowpea, aiming at to support selection and breeding strategies to obtain high yield and drought tolerant elite varieties.

\section{Introduction}

World population is projected to reach $c a$. 9.800 million around 2050 (FAO - Food and Agriculture Organization of the United Nations (2009); FAO - Food and Agriculture Organization of the United Nations, 2011), bringing along a high pressure on land and water resources for food and feed production (FAO - Food and Agriculture Organization of the United Nations, 2016; Tian et al., 2016; IFPRI - International Food Policy Research Institute, 2019; Pais et al., 2020). This will constitute an enormous challenge, particularly in Sub-Saharan Africa, where the population is estimated to double by 2050 (UN -United Nations, 2019), and are expected strong impacts of climate changes on the predominant rain fed and low external input agricultural systems (Mendelsohn, 2008; Müller et al., 2011).

Despite the advances to unveil drought response mechanisms from gene to the whole plant (Chaves et al., 2003), and across the soil-plantatmosphere complex (Chaves and Oliveira, 2004; Chaves and Zarrouk, 2012; Mundim and Pringle, 2018), drought is still one of the major yield constraints, turning crucial to select and improve tolerant cultivars with both short- and long-term acclimation mechanisms to water shortage episodes (Chaves et al., 2003; Hasan et al., 2018). Drought impairs most morphological, physiological and biochemical processes in plants, reducing plant growth, nutrient uptake, photosynthesis, and assimilate partitioning, therefore strongly reducing crop productivity (Fahad et al., 2017; Lamaoui et al., 2018). Under mild drought, reduced stomatal opening is among the first plant responses, avoiding additional water loss through the transpiration, but also limiting the $\mathrm{CO}_{2}$ supply to ribulose 1,5-bisphosphate carboxylase/oxygenase (RuBisCO), thus, causing metabolic down-regulation and reducing net photosynthesis. Harsher drought conditions will progressively impose non-stomatal limitations on the photosynthetic pathway, due to impairments in the chloroplast components, namely, in membrane integrity and lipid composition, photosynthetic pigments, photosystems (PSs) efficiency, and key enzymes activity, including in RuBisCO (Chaves et al., 2003; Muller et al., 2011; Scotti-Campos et al., 2013; Ramalho et al., 2014; Fahad et al., 2017). In plants with a higher acclimation ability, such limited photochemical energy use can thereafter trigger, among others, thermal dissipation and photoprotective mechanisms, cyclic electron flow, and increase the presence of antioxidative molecules (e.g., enzymes, carotenoids) (Chaves and Oliveira, 2004; Reddy et al., 2004; Ramalho et al., 2018).

Cowpea (Vigna unguiculata (L.) Walp.) is a multipurpose legume providing high-quality protein food for human consumption, proteinrich fodder for livestock and plays an important role in soil nutrient cycling through biological nitrogen fixation (Boukar et al., 2015). Dry grain has $23-32 \%$ protein and is also rich in essential amino-acids such as tryptophan and lysine, with 68 and $427 \mathrm{mg} \mathrm{g}^{-1} \mathrm{~N}$ respectively (Carvalho et al., 2017). In Africa, cowpea dry grain is an accessible protein source for low income populations, thus being commonly designated as "poor man's meat" (Fall et al., 2003). Despite being originally from Africa, cowpea is now cropped worldwide in more than 100 countries (Gonçalves et al., 2016), with a global yield estimated of 9.8 million tons by 2020, rising to 12.3 million tons by 2030 (Boukar et al., 2016).

The large cowpea genetic pool in Africa is of crucial importance for the implementation of selection and breeding programs, targeting the development of high yielding and water efficient elite cultivars adapted to the prevalent biotic and abiotic stresses (Blum, 2009; Gomes et al.,
2019), and to the (mostly) low technological and rain fed agricultural systems of this continent Studies in cowpea regarding stress impact in the photosynthetic apparatus gather relevant information, namely through the use of non-destructive in vivo techniques, as leaf gas exchanges and chlorophyll (Chl) $a$ fluorescence parameters (Campos et al., 1999; Scotti-Campos et al., 2013). Recently, metabolite profiling has been gaining space to study drought response mechanisms, improving genotype selection and identifying drought tolerance proxies (Degenkolbe et al., 2013). Efforts have been made to predict drought tolerance on the analysis of, namely, amino-acid responses in wheat (Nagy et al., 2013; Yadav et al., 2019), tricarboxylic acid (TCA) cycle intermediates in Arabidopsis (Pires et al., 2016), and proline and glycolate in beans, cowpea, cotton and forage legumes (Rosales et al., 2012; Sanchez et al., 2012; Goufo et al., 2017; Hasan et al., 2018). Significant reductions in serine, threonine, aspartic acid and glutamic acid content were also reported in droughted plants (Asai et al., 2017; Yadav et al., 2019). Altogether, these studies showed that highthroughput targeted metabolite profiling is a valuable tool for genotype selection.

In Africa, limited information is available on stress responses of locally grown crops to most environmental stressors, particularly drought. In this context, this work aims at integrate physiological, biochemical (both related to the photosynthetic machinery performance), and primary metabolite profile changes to better understand the cowpea response mechanisms to drought. Such integrative approach is expected to allow the identification drought tolerance bioindicators that can be used to speed the selection and breeding programs. In this context, the present study investigated the impact of mild (MD) and severe (SD) water restriction levels in three cowpea landraces with contrasting drought tolerance (A55 - high sensitivity; A80 - mild sensitivity; A116 - tolerant), from three agro-ecological zones of Central Mozambique. This was be done through the analysis of photosynthesis related parameters (leaf gas exchanges, $\mathrm{Chl} a$ fluorescence, RuBisCO activity), which are important drought targets, as well as the evaluation of the changes in leaf primary metabolite profile, followed by a PCA and PLS-DA tests to assure the robustness of the identification of effective probes for drought tolerance in cowpea.

\section{Materials and methods}

\subsection{Brief plant material characterization}

The three studied cowpea landraces are widely cultivated across Central Mozambique, and display field contrasting capability to endure drought A55 (high sensitivity), A80 (mild sensitivity) and A116 (tolerant), but having similar flowering times. The seeds and their brief characterization were obtained from the cowpea seedbank of the Faculty of Agriculture of the Instituto Superior Politécnico de Manica, Mozambique, as it follows. A55 is a cream coloured and ovoid shaped grain with a smooth testa texture and absent eye pattern and colour. Average seed length, width and thickness of A55 was of $6.87 \pm 0.45$, $6.26 \pm 0.30$, and $4.91 \pm 0.43 \mathrm{~mm}$, respectively, showing the highest 100 kernels weight of the three landraces $(15.11 \mathrm{~g})$. A80 is a rhomboid shaped and cream coloured grain with a smooth testa texture, and absent eye pattern and colour. A80 seed length, width and thickness were the highest among the three landraces, averaging $8.51 \pm 0.36$, $7.00 \pm 0.35$, and $4.75 \pm 0.40 \mathrm{~mm}$, respectively. A80 kernel weight was second to A55 with $14.25 \mathrm{~g}$ per 100 seeds. A116 is characterized by 
moatted dark coloured grains with a smooth testa texture and absent eye pattern and colour. A116 presented the lowest 100 kernels weight $(12.88 \mathrm{~g})$, and averages for seed length, width and thickness of $8.25 \pm 0.31,6.23 \pm 0.33$, and $4.29 \pm 0.17 \mathrm{~mm}$, respectively. The three landraces have a semi-erect growth habit, sub-globose (A116) and subhastate (A55, A80) terminal leaf shape, and short appressed hairness. All landraces have leaves with a pale green colour and coriaceous texture, yellow flowers, and low early rust susceptibility. All entries in the seedbank were morphologically characterized based on the descriptors for cowpea from the International Board for Plant Genetic Resources (IBPGR - International Board for Plant Genetic Resources, 1983).

\subsection{Growth conditions and experimental design}

Seeds from A55, A80 and A116 landraces were sown in $9 \mathrm{~L}$ pots in a substrate consisting of a mixture of soil, peat, and sand (3:1:3, v/v/v). and grown in a walk in growth chamber (EHHF 10,000; ARALAB, Portugal), under controlled conditions of temperature $\left(25 / 20{ }^{\circ} \mathrm{C}\right.$, day/ night), irradiance ( $c a .600 \mu \mathrm{mol} \mathrm{m}^{-2} \mathrm{~s}^{-1}$ ), RH (65\%), photoperiod (12 h), and air $\left[\mathrm{CO}_{2}\right]\left(400 \mu \mathrm{L} \mathrm{L}^{-1}\right)$, and maintained under well-watered conditions. The experiment was established as a factorial design considering two factors: three cowpea landraces (A55, A80 and A116), and three water availability levels (well-watered or control - WW; mild drought - MD; severe drought - SD), with five pots per treatment (each one with two plants). Based on results from a pilot study to establish drought regimes, the drought imposition started 28 days after sowing (D28), when plants began branching, until early pod setting. The pots were weighed every day, with control (WW) being maintained at $100 \%$ field capacity with a total compensation of daily evapotranspirated water, whereas MD and SD conditions were gradually imposed along 2 weeks, by compensating only part of the evapotranspirated water in each pot until reaching $50 \%$ and $10 \%$ of field capacity, respectively. These conditions were maintained for one week before programmed evaluations were carried out on newly matured leaves from the upper part of the plant. Except for leaf water status (determined at predawn), leaf material was analysed or collected after $c a .2 \mathrm{~h}$ of illumination under steady-state photosynthetic conditions. Whenever possible, the leaves used for non-destructive analysis (gas exchanges and fluorescence analysis) were afterwards collected for destructive analysis (pigments, enzyme, and metabolite analysis).

\subsection{Leaf water status}

The predawn leaf relative water content $[$ RWC $(\%)=(F W-D W /$ TW - DW) x100] was determined as described elsewhere (Ramalho et al., 2018). Briefly, samples of ten leaf discs $\left(0.5 \mathrm{~cm}^{2}\right.$ each), from five plants per treatment, were immediately cut after leaf excision. Fresh weight (FW) was assessed immediately after cutting the discs; turgid weight (TW) after overnight discs rehydration in a humid chamber at room temperature $\left(\mathrm{ca} .20^{\circ} \mathrm{C}\right)$; dry weight (DW) after drying the discs at $80{ }^{\circ} \mathrm{C}$ for $24 \mathrm{~h}$.

\subsection{Leaf gas exchanges}

The leaf rates of net photosynthesis $\left(\mathrm{P}_{\mathrm{n}}\right)$, stomatal conductance to water vapor $\left(\mathrm{g}_{\mathrm{s}}\right)$, and transpiration $\left(\mathrm{T}_{\mathrm{r}}\right)$ were measured under photosynthetic steady-state conditions in 2 leaves from each five plants per treatment (one per pot), using a portable open-system infrared gas analyser (CIRAS 1, PP System, USA), under $400 \mu \mathrm{L} \mathrm{CO}_{2} \mathrm{~L}^{-1}$ and irradiance of $c a .500 \mu \mathrm{mol} \mathrm{m}^{-2} \mathrm{~s}^{-1}$. Additionally, under this ambient irradiance condition, the $\left[\mathrm{CO}_{2}\right]$ was gradually increased in the CIRAS 1 leaf chamber until maximal net photosynthesis $\left(\mathrm{P}_{\mathrm{nmax}}\right)$ was obtained, what occurred always up to $1500 \mu \mathrm{L} \mathrm{CO}_{2} \mathrm{~L}^{-1}$. Leaf instantaneous water use efficiency (iWUE) was calculated as the $\mathrm{P}_{\mathrm{n}} / \mathrm{T}_{\mathrm{r}}$ ratio, representing the units of assimilated $\mathrm{CO}_{2}$ per unit of water lost through transpiration.

\subsection{Chlorophyll a fluorescence analysis}

Chlorophyll (Chl) $a$ fluorescence parameters were determined immediately after gas exchange measurements, on the same leaves and environmental conditions, using a PAM2000 system (Walz, Effeltrich, Germany) as previously described (Martins et al., 2016; Rodrigues et al., 2016). For calculations were used the formulae referred elsewhere (Adams III and Demmig-Adams, 2004; Kramer et al., 2004; Krause and Jahns, 2004; Schreiber, 2004). In brief, measurements of minimum fluorescence from antennae $\left(\mathrm{F}_{\mathrm{o}}\right)$ and maximal photochemical efficiency of PSII $\left(\mathrm{F}_{\mathrm{v}} / \mathrm{F}_{\mathrm{m}}\right)$ were performed on overnight dark-adapted leaves. $\mathrm{F}_{\mathrm{o}}$ is the fluorescence emission from excited $\mathrm{Chl} a$ molecules, before photochemical events, with $\mathrm{Q}_{\mathrm{A}}$ in the oxidised state, beings determined using weak light $\left(<0.5 \mu \mathrm{mol} \mathrm{m}{ }^{-2} \mathrm{~s}^{-1}\right)$. $\mathrm{F}_{\mathrm{m}}$ corresponds to complete reduction of the primary PSII acceptors and full closure of PSII photochemical traps. $\mathrm{F}_{\mathrm{v}} / \mathrm{F}_{\mathrm{m}}$ represents the maximum PSII photochemical efficiency and was obtained using a $0.8 \mathrm{~s}$ pulse of $c a .7500$ $\mu \mathrm{mol} \mathrm{m} \mathrm{m}^{-2} \mathrm{~s}^{-1}$ of actinic light (previously found as saturating).

A second set of parameters was evaluated under photosynthetic steady-state conditions, under an irradiance of $c a .500 \mu \mathrm{mol} \mathrm{m} \mathrm{m}^{-2} \mathrm{~s}^{-1}$, and superimposed saturating flashes, considering the parameters $q_{L}, q_{N}$, $\mathrm{Y}_{(\mathrm{II})}, \mathrm{Y}_{(\mathrm{NPQ})}, \mathrm{Y}_{(\mathrm{NO})}$ and $\mathrm{F}_{\mathrm{v}}{ }^{\prime} / \mathrm{F}_{\mathrm{m}}$ ' (Kramer et al., 2004; Klughammer and Schreiber, 2008), $\mathrm{F}_{\mathrm{s}} / \mathrm{F}_{\mathrm{m}}$ ' (Stirbet and Govindjee, 2011), and the PSII photoinhibition indexes (Werner et al., 2002). The $\mathrm{F}_{\mathrm{v}}{ }^{\prime} / \mathrm{F}_{\mathrm{m}}$ ' represents the actual PSII efficiency of energy conversion under light exposure. $\mathrm{q}_{\mathrm{L}}$ is the proportion of energy trapped by PSII open centers and driven to photochemical events, based on the concept of interconnected PSII antennae. $\mathrm{q}_{\mathrm{N}}$ is the non-photochemical quenching, which reflects the sustained, photoprotective thermal energy dissipation. Estimates of the quantum yields of photosynthetic non-cyclic electron transport $\left(\mathrm{Y}_{(\mathrm{II})}\right)$, of regulated energy dissipation of PSII $\left(\mathrm{Y}_{(\mathrm{NPQ})}\right)$, and of non-regulated energy $\left(\mathrm{Y}_{(\mathrm{NO})}\right)$ dissipation of PSII were provided, knowing that $\left[\mathrm{Y}_{(\mathrm{II})}+\right.$ $\mathrm{Y}_{(\mathrm{NPQ})}+\mathrm{Y}_{(\mathrm{NO})}=1$ ] (Kramer et al., 2004; Huang et al., 2012). Additionally, the following parameters were calculated: the predictor of the rate constant of PSII inactivation, $\mathrm{F}_{\mathrm{s}} / \mathrm{F}_{\mathrm{m}}$ ' (Stirbet and Govindjee, 2011) and the PSII photoinhibition indexes (Werner et al., 2002) that included dynamic photoinhibition $\left(\mathrm{PI}_{\mathrm{Dyn}}\right)$, chronic photoinhibition $\left(\mathrm{PI}_{\mathrm{Chr}}\right)$, and total photoinhibition $\left(\mathrm{PI}_{\mathrm{Total}}=\mathrm{PI}_{\mathrm{Chr}}+\mathrm{PI}_{\text {Dyn }}\right)$.

\subsection{Photoprotective pigment evaluation}

Carotenoids (Car) were quantified as described elsewhere (Ramalho et al., 2014) using samples of four leaf discs $\left(0.5 \mathrm{~cm}^{2}\right.$ each), cut under photosynthetic steady-state conditions, from 2 leaves from each five plants per treatment (one per pot), and immediately frozen in liquid nitrogen and stored at $-80{ }^{\circ} \mathrm{C}$ until analysis. Briefly, sample processing and subsequent reverse-phase HPLC analysis were carried out using an end-capped $\left(\mathrm{C}_{18}\right) 5 \mu \mathrm{m}$ Spherisorb ODS-2 column $(250 \times 4.6 \mathrm{~mm}$, Waters, USA). Detection was performed at $440 \mathrm{~nm}$ using an HPLC system (Beckman, System Gold, USA) coupled to a diode-array detector (Model 168, Beckman). Identification and quantification were made from individual standards for each specific pigment. The de-epoxidation state (DEPS), involving xanthophyll cycle components, was calculated as DEPS $[=$ (Zeaxanthin +0.5 Antheraxanthin $) /($ Violaxanthin + Antheraxanthin + Zeaxanthin)].

\subsection{Ribulose-1,5-bisphosphate carboxylase/oxygenase activities}

Determinations of ribulose-1,5-bisphosphate carboxylase/oxygenase enzymatic activities (RuBisCO; EC 4.1.1.39) adapted from Ramalho et al. (2013). Briefly, leaf samples from five plants per treatment (one per pot) were collected and immediately frozen in liquid nitrogen and stored at $-80{ }^{\circ} \mathrm{C}$ until analysis. Leaf material was finely powdered in liquid nitrogen, and aliquots of $c a .100 \mathrm{mg} \mathrm{FW}$ were taken and homogenized in a cooled mortar using ca. $100 \mathrm{mg}$ insoluble PVPP and $1 \mathrm{~mL}$ extraction buffer consisting of $100 \mathrm{mM}$ Tris $-\mathrm{HCl}(\mathrm{pH} 8)$, 
which contained $10 \mathrm{mM} \mathrm{MgCl} 2,15 \mathrm{mM} \mathrm{NaHCO} 3,10 \mathrm{mM} \beta$-mercaptoethanol, $2 \mathrm{mM}$ DTT, 1\% (v/v) Triton X-100, 2), $10 \%$ (v/v) glycerol and $2 \%(\mathrm{v} / \mathrm{v})$ "Complete-protease inhibitor cocktail" (to protect enzymes from protease action) (Roche, ref. 04693159001). The extracts were then centrifuged $\left(16000 \mathrm{~g}, 15 \mathrm{~min}, 4{ }^{\circ} \mathrm{C}\right)$, and the obtained clean supernatant was used for enzyme activity determinations. For these it was used an assay medium of $50 \mathrm{mM}$ Tris - $\mathrm{HCl}$ buffer, $\mathrm{pH}$ 8.0, $15 \mathrm{mM}$ $\mathrm{MgCl}_{2}, 20 \mathrm{mM} \mathrm{NaHCO}$, $100 \mathrm{mM}$ phosphocreatine, $10 \mathrm{mM}$ ATP, 0.2 mM NAPH, $20 \mathrm{U} \mathrm{mL}^{-1}$ creatine kinase, $15 \mathrm{U} \mathrm{mL}^{-1}$, 3-phosphoglycerate kinase, and $15 \mathrm{U} \mathrm{mL}^{-1}$ glyceraldehyde-3-phosphate dehydrogenase.

To obtain initial RuBisCO activity, $10 \mathrm{mM}$ RuBP was added, and then $20 \mu \mathrm{L}$ of sample supernatant, followed by immediate reading. To obtain total RuBisCO activity, $20 \mu \mathrm{L}$ of the clean supernatant was added to the assay medium, followed by a $20 \mathrm{~min}$ incubation period, after which the reaction was started with addition of $10 \mathrm{mM}$ RuBP.

In both cases, spectrophotometric measurements were performed in a final volume of $1 \mathrm{~mL}$, and followed the 3-PGA-dependent NADH oxidation at $340 \mathrm{~nm}$, at $25{ }^{\circ} \mathrm{C}$.

\subsection{GC-TOF-MS primary metabolite profiling}

Primary metabolites were extracted following a previously described protocol (Lisec et al., 2006; Jorge et al., 2017). Briefly, 3 pools of leaves (each one from 3 cowpea plants) per treatment were collected, flash frozen in liquid nitrogen and stored at $-80{ }^{\circ} \mathrm{C}$ until analysis. Afterwards, samples were finely powdered in liquid nitrogen, and aliquots of $c a .100 \mathrm{mg}$ (FW) were taken into $2.0 \mathrm{~mL}$ safe-lock polypropylene microfuge tubes (Eppendorf, Hamburg, Germany). Primary metabolites were then extracted using $1400 \mu \mathrm{L}$ of methanol (100\%) containing ribitol $\left(0.2 \mathrm{mg} \mathrm{mL}^{-1}\right.$ in water) as internal standard. The mixture was incubated on a shaker at $70{ }^{\circ} \mathrm{C}$ for $15 \mathrm{~min}$ at $950 \mathrm{rpm}$ (Thermomixer C, Eppendorf), and centrifuged $\left(11,000 \mathrm{~g}, 10 \mathrm{~min}, 25^{\circ} \mathrm{C}\right)$ (Centrifuge 5430, Eppendorf). The supernatant was transferred to a glass vial (Schott GL14, Mainz, Germany) and $750 \mu \mathrm{L}$ of chloroform were added followed by $1500 \mu \mathrm{L}$ of distilled water. The resulting mixture was vortex-mixed for $15 \mathrm{~s}$ and centrifuged $(2200 \mathrm{~g}, 15 \mathrm{~min}, 25$ ${ }^{\circ} \mathrm{C}$ ) (Centrifuge 5810R, Eppendorf). A total of $150 \mu \mathrm{L}$ of the upper phase (polar phase) of each sample were evaporated to dryness using a vacuum concentrator (Vacufuge Plus, Eppendorf) for $3 \mathrm{~h}$ at $30^{\circ} \mathrm{C}$. Primary metabolites were derivatized and analysed using a well-established gas chromatography time of flight mass spectrometry (GC-TOF-MS) protocol (Lisec et al., 2006). Biological variations were controlled by analysing quality control (QC) standards by fatty acid methyl esters internal standard markers and a QC standard solution of 41 pure reference compounds (i.e., the most detected and abundant metabolites) throughout the analysis.

After GC-TOF-MS analysis, the obtained files (.cdf format) for each sample were subsequently evaluated at using AMDIS (Automated Mass Spectral Deconvolution and Identification System) software (v 2.71). Primary metabolites were annotated using the TagFinder software (Luedemann et al., 2008) and a reference library of ambient mass spectra and retention indices from the Golm Metabolome Database (http://gmd.mpimp-golm.mpg.de/) (Kopka et al., 2004; Schauer et al., 2005). The relative abundance of primary metabolite levels was normalized to the internal standard (ribitol) and the fresh weight of the samples. Hierarchical clustering analysis was performed in R software ( $\mathrm{R}$ Core Team, 2016) using the 'heatmap.2' function from the 'gplots' package (Warnes et al., 2016).

\subsection{Statistical analysis}

The various measured and calculated parameters were analysed using two-way ANOVAs to evaluate the differences between water availability treatments, between landraces, and their interaction, followed by a Tukey test for mean comparisons, between landraces within the same water treatment, and between water treatments within the same genotype. A $95 \%$ confidence level was adopted for both tests.

For metabolomic data, significant differences between WW, MD, and SD samples were estimated with Student $t$-test $(p<0.05)$ using the R-software (R Core Team, 2016). Principle Component Analysis (PCA) and Partial Least Squares Discriminant Analysis (PLS-DA) were obtained using the R software package mixOmics (Rohart et al., 2017).

\section{Results}

\subsection{Leaf water status}

Different water availability levels were effectively imposed to the plants of all landraces, as reflected in the gradual but significant decrease in RWC predawn values, as compared to their respective WW

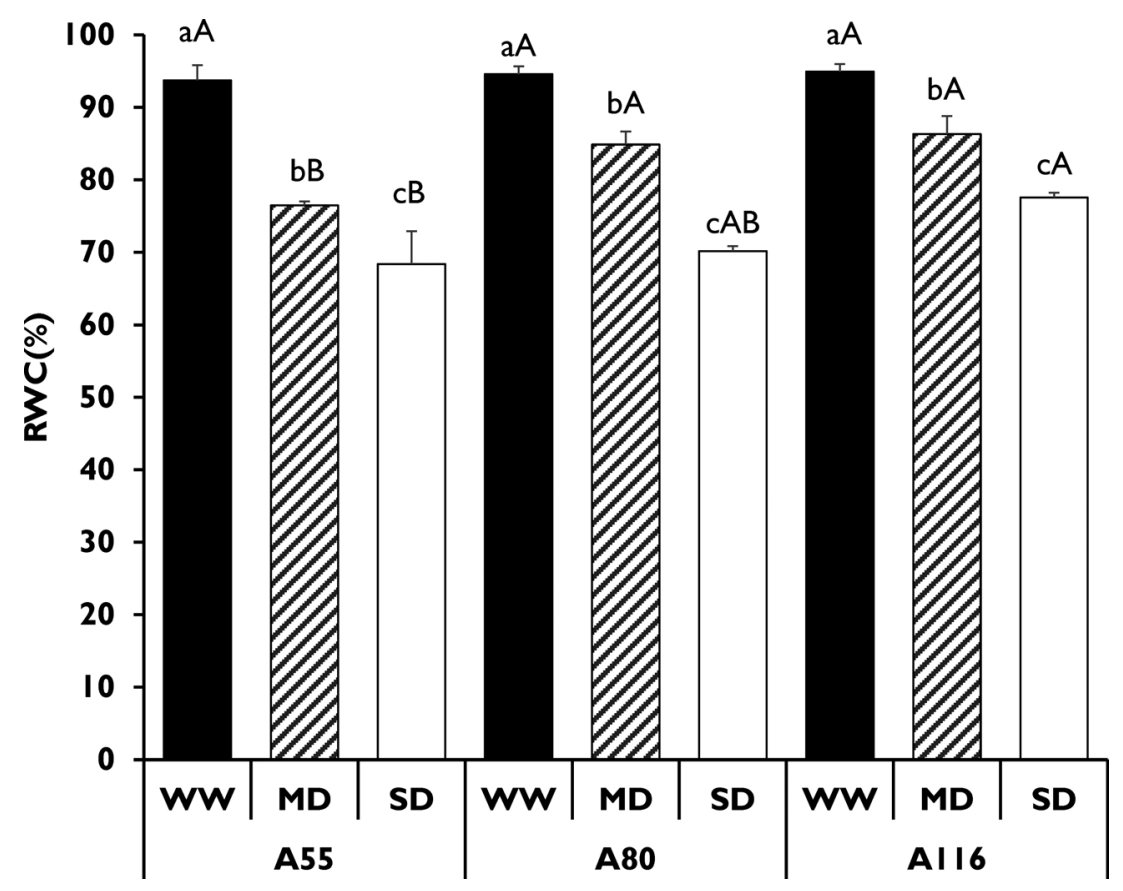

Fig. 1. Variation of predawn relative water content (RWC) in three cowpea landraces (A55, A80, A116) under well-watered (WW), mild (MD), and severe (SD) drought conditions. Values representing the mean $\pm S E(n=4)$ followed by different letters express significant differences between water treatments within each genotype $(a, b, c)$, or between the three landraces within each water condition (A, B, C). 
controls (Fig. 1), with the lowest values observed in SD plants. Among landraces, A55 showed stronger RWC declines among MD and SD plants, with reductions of 17.3 and $25.4 \%$, respectively. By contrast, A116 suffered the smallest reductions in MD (8.6\%) and SD (17.4\%) plants, that is, under the same reductions to $50 \%$ and $10 \%$ field capacity, respectively. A80 showed intermediate dehydration values, with their RWC values not differing from A116 in MD and SD plants, and from A80 SD plants.

\subsection{Leaf gas exchanges}

Both drought levels provoked significant reductions in the assimilation rate $\left(\mathrm{P}_{\mathrm{n}}\right)$ in all landraces (Fig. 2A). With the exception of A116 MD plants, droughted (MD and SD) plants showed $P_{n}$ negligible (or even negative) values. This closely followed the strong reductions of $g_{s}$, $\mathrm{T}_{\mathrm{r}}$ and iWUE (Fig. 2B-D) to values close to zero in MD and SD plants, without noticeable differences among landraces. Additionally, $\mathrm{P}_{\mathrm{nmax}}$ obtained under saturating $\left[\mathrm{CO}_{2}\right]$, showed as well significant reductions, although differently among landraces and drought levels (Fig. 2A). Under MD conditions, the greatest $\mathrm{P}_{\text {nmax }}$ impact was observed in A55 plants, which showed a $94 \%$ reduction, whereas A116 presented the smallest reduction (53\%), and A80 displayed an intermediate decline (66\%). With harsher drought conditions (SD) all landraces showed reductions of $c a$. $94 \%$, as compared to their respective controls.

\subsection{Chlorophyll a fluorescence analysis}

No genotypic variability was observed in WW plants with respect to $F_{o}$ values (Table 1), but drought promoted a rising tendency, which becomes significant under SD conditions in all landraces. This reduced the maximal PSII photochemical efficiency $\left(\mathrm{F}_{\mathrm{v}} / \mathrm{F}_{\mathrm{m}}\right)$, and resulted in an absence of significant differences between landraces under the harshest drought conditions.

Under photosynthetic steady-state conditions, the actual PSII photochemical efficiency $\left(\mathrm{F}_{\mathrm{v}}{ }^{\prime} / \mathrm{F}_{\mathrm{m}}{ }^{\prime}\right)$ showed high values under WW conditions, but upon water restriction only A55 and A116 plants revealed significant reductions of 26 and $18 \%$, respectively, already under MD. Under SD, the $\mathrm{F}_{\mathrm{v}}{ }^{\prime} / \mathrm{F}_{\mathrm{m}}{ }^{\prime}$ was significantly reduced (35-40\%) in all landraces, although relevant PSII functioning was kept.

Differences between landraces emerged as regards the energy driven to photochemical events $\left(\mathrm{q}_{\mathrm{L}}\right)$, which was significantly higher in A116 plants under all water conditions, although gradually decreased with drought imposition in all landraces except A80 that maintained low values irrespective of water availability. Also, A55 plants showed the minimal value among the three landraces under SD conditions, and were the only ones to be significantly affected under MD (with a $78 \%$ fall).

The quantum yield of photosynthetic non-cyclic electron transport $\left(\mathrm{Y}_{(\mathrm{II})}\right)$ followed a quite close pattern of variation to that of $\mathrm{q}_{\mathrm{L}}$ as regards the water restriction treatments. Again, A55 was the greatest affected genotype, showing the lowest values under MD and SD conditions, resulting from $81 \%$ and $87 \%$ reductions, respectively. In the latter conditions all landraces were significantly affected, without significant differences between them, although A116 maintained a $75 \%$ higher value than A55.

To complement the analysis focusing light energy use, some parameters related with thermal dissipative mechanisms were also calculated. The $\mathrm{q}_{\mathrm{N}}$ values gradually increased with the growing water restriction, quite similarly in A55 and A116. A80 displayed an unusual $\mathrm{q}_{\mathrm{N}}$ high value in WW plants, which was maintained along the experiment, but no significant differences were observed in MD and SD between landraces. The $\mathrm{Y}_{(\mathrm{NPQ})}$ presented a similar rising pattern than $\mathrm{q}_{\mathrm{N}}$ in response to drought, but A55 showed the highest values in MD and SD plants, and A116 the lowest values, both without statistical difference to $A 80$. Notably, $\mathrm{Y}_{(\mathrm{NO})}$, reflecting potential deleterious impacts, did not rise in both A55 and A116 in either drought conditions. Despite the significant $\mathrm{Y}_{(\mathrm{NO})}$ increase in A80 under SD conditions, the values observed in all landraces can be considered quite normal.

As expected, the rate constant of PSII inactivation $\left(\mathrm{F}_{\mathrm{s}} / \mathrm{F}_{\mathrm{m}}{ }^{\prime}\right)$ followed an opposite pattern of that shown by $\mathrm{F}_{\mathrm{v}}{ }^{\prime} / \mathrm{F}_{\mathrm{m}}$ ', although with a quite high value in A80 plants already under WW conditions (similarly to $\mathrm{q}_{\mathrm{N}}$, and $\left.\mathrm{Y}_{(\mathrm{NPQ})}\right)$. The greatest increases and highest $\mathrm{F}_{\mathrm{s}} / \mathrm{F}_{\mathrm{m}}$ ' values were observed
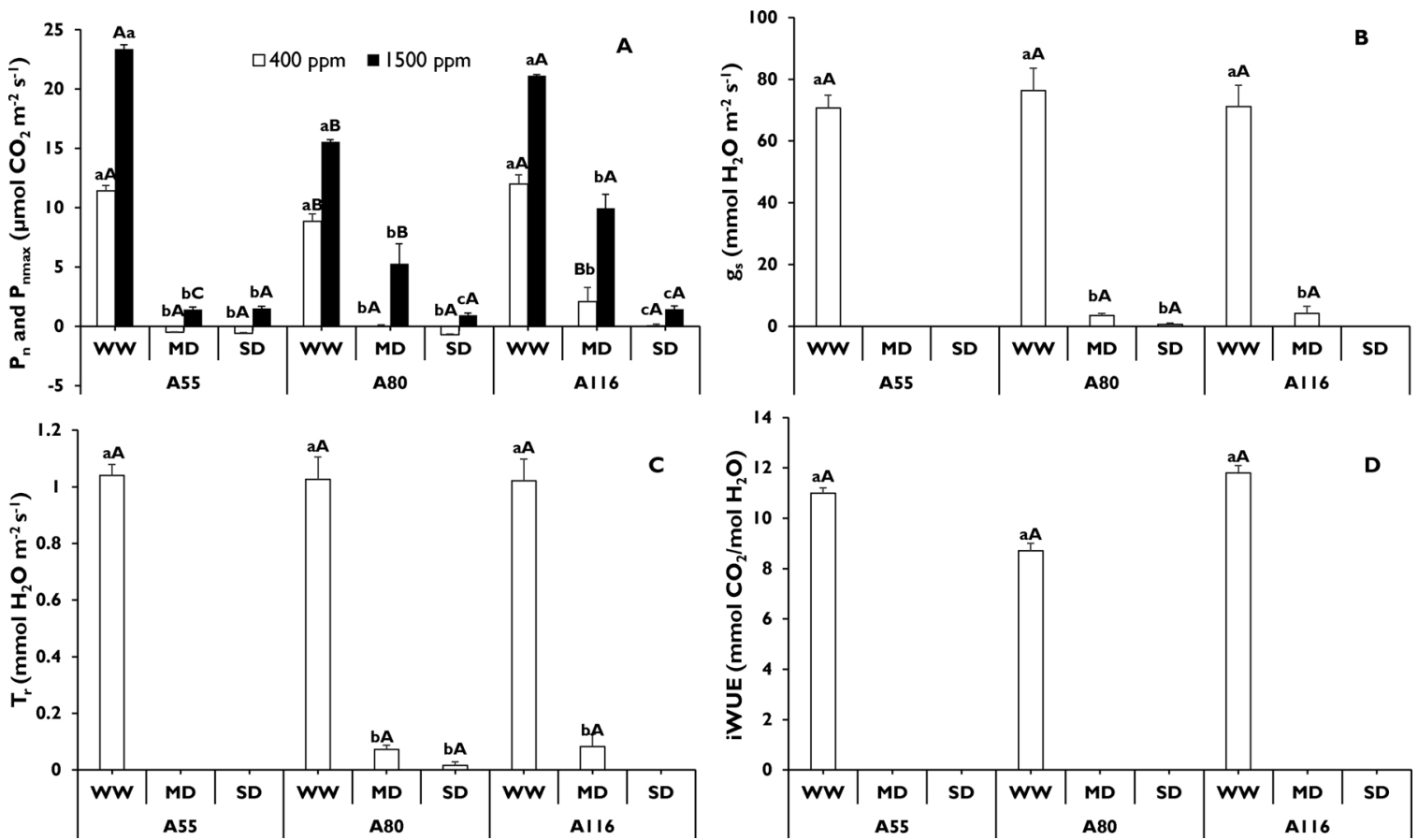

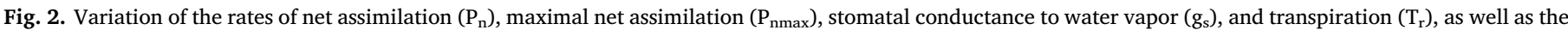

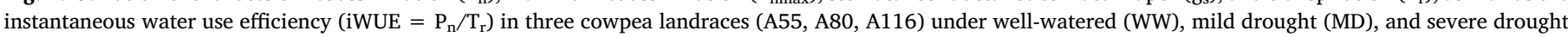

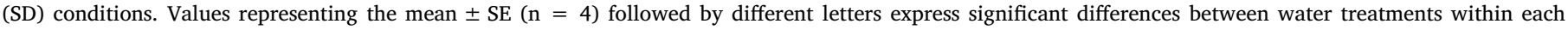
genotype $(a, b, c)$, or between the three landraces within each water condition (A, B, C). 
Table 1

Analysis of chlorophyll $a$ fluorescence parameters in three cowpea landraces (A55, A80, A116) under well-watered (WW), mild drought (MD), and severe drought (SD) conditions. Parameters are the minimal fluorescence from the antennae $\left(\mathrm{F}_{o}\right)$, maximal photochemical efficiency of PS II $\left(\mathrm{F}_{\mathrm{v}} / \mathrm{F}_{\mathrm{m}}\right)$, actual PS II efficiency of energy conversion under light $\left(\mathrm{F}_{\mathrm{v}}{ }^{\prime} / \mathrm{F}_{\mathrm{m}}{ }^{\prime}\right)$, non-photochemical quenching $\left(\mathrm{q}_{N}\right)$, photochemical quenching, based on the concept of interconnected PS II antennae $\left(\mathrm{q}_{L}\right)$, estimate of the quantum yield of photosynthetic noncyclic electron transport $\left(\mathrm{Y}_{(\mathrm{II})}\right)$, estimate of the quantum yields of photosynthetic non-cyclic electron transport $\left(\mathrm{Y}_{(\mathrm{III})}\right)$, and of regulated $\left(\mathrm{Y}_{(\mathrm{NPQ})}\right)$ and non-regulated $\left(\mathrm{Y}_{(\mathrm{NO})}\right)$ energy dissipation of PSII. The predictor of the rate constant of PSII inactivation $\left(\mathrm{F}_{\mathrm{s}} / \mathrm{F}_{\mathrm{m}}\right.$ '), chronic photoinhibition $\left(\mathrm{PI}_{\mathrm{Chr}}\right)$, dynamic photoinhibition $\left(\mathrm{PI}_{\mathrm{Dyn}}\right.$ and total photoinhibition $\left(\mathrm{PI}_{\text {Total }}=\mathrm{PI}_{\mathrm{Chr}}+\mathrm{PI}_{\mathrm{Dyn}}\right)$ were also provided. Values representing the mean $\pm \mathrm{SE}(\mathrm{n}=4)$ followed by different letters express significant differences between water treatments within each genotype (a, b, c), or between the three landraces within each water condition (A, B, C).

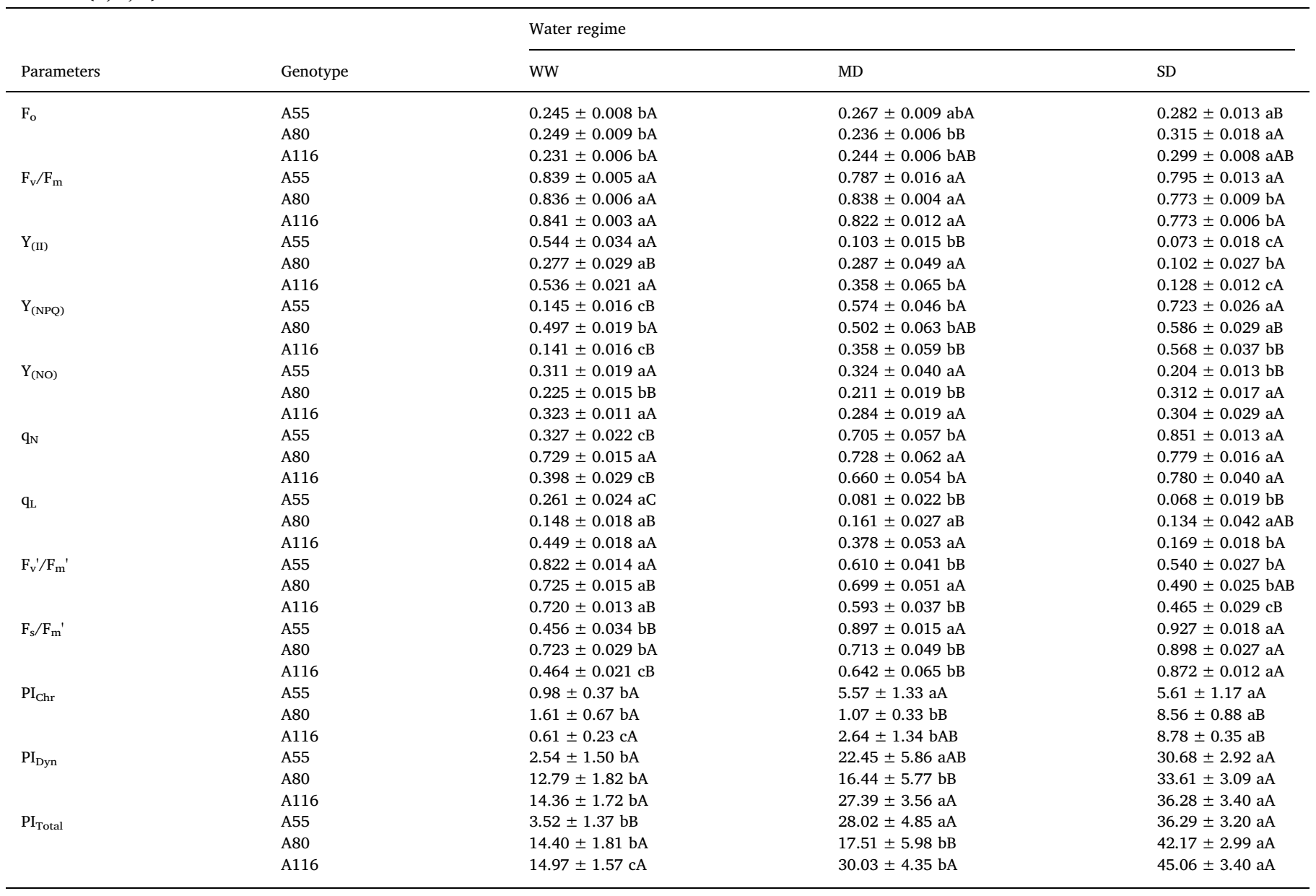

in A55 plants, that under MD and SD conditions approximately doubled the WW values. However, under the harshest drought exposure no significant differences were observed between landraces regarding PSII inactivation.

In line with the pattern of controlled dissipation mechanisms, the dynamic PSII photoinhibition $\left(\mathrm{PI}_{\mathrm{Dyn}}\right)$ gradually increased with the growing drought severity, showing maximal (and similar) values in all landraces under SD conditions. Chronic PSII photoinhibition ( $\mathrm{PI}_{\mathrm{Chr}}$ ) showed significant increases in MD (A55, A116), and SD (all landraces) conditions, but it must be underlined that even the highest $\mathrm{PI}_{\mathrm{Chr}}$ values observed in SD can be considered quite low, what agrees with the moderate $\mathrm{Y}_{(\mathrm{NO})}$ changes, and the maintenance of relevant $\mathrm{F}_{\mathrm{v}}{ }^{\prime} / \mathrm{F}_{\mathrm{m}}$ ' values. Finally, total photoinhibition $\left(\mathrm{PI}_{\text {Total }}\right)$ significantly increased in MD (A55, A116), and SD (all landraces) conditions, with A80 showing the lowest value in MD, but without significant differences between landraces under SD conditions.

\subsection{Photoprotective pigment evaluation}

Total carotenoids content differed across landraces with A55 showing the highest content in all water conditions, whereas no significant differences were found between A80 and A116 (Table 2).
Notably, drought promoted strong increases of total carotenoids in all landraces at MD and thereafter, reaching $32 \%$ (A55) and $40 \%$ (A80 and A116) higher values under SD conditions, as compared with their respective WW plants.

This common global carotenoid increase resulted mostly from the simultaneous increases of neoxanthin, $\alpha$-carotene, and, especially, zeaxanthin (Z) and lutein, with the latter representing almost half of all carotenoids content. Maximal values of lutein were observed under SD conditions due to increases between $36.5 \%$ (A55 and A80) and $45 \%$ (A116), whereas neoxanthin increased ca. $12-13 \%$ in all landraces. However, $\mathrm{Z}$ was the most responsive pigment to drought, especially in MD plants that reached 3 (A116), 9 (A55) and 20 fold (A80) higher values than their respective $W W$ values, with a consequent strong rise in the de-epoxidation state (DEPS). These $\mathrm{Z}$ increases resulted from the transformation of previous existing violaxanthin (V), which in turn was reduced, but also from de novo synthesis from the xanthophyll pool, as reflected in the rise of the $(\mathrm{V}+\mathrm{A}+\mathrm{Z})$ pool content between $31 \%$ (A116) and $87 \%$ (A80) in SD plants. Furthermore, this rise resulted in a higher weight of the $(\mathrm{V}+\mathrm{A}+\mathrm{Z})$ pool among total carotenoids in the droughted plants of A55 and A80.

Among carotenes, $\alpha$-carotene was increased in all landraces by $14 \%$ (A55), $35 \%$ (A80) and $86 \%$ (A116), in SD conditions, significantly 
Table 2

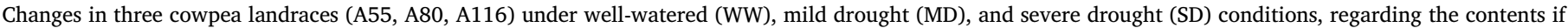

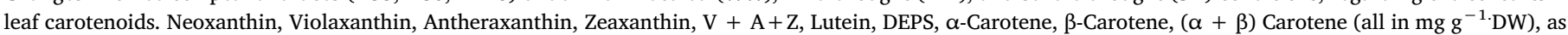

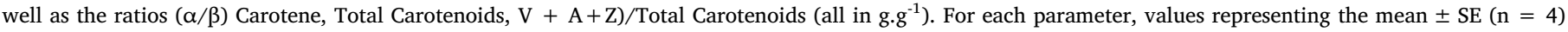

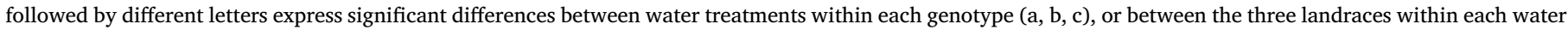
condition (A, B, C).

\begin{tabular}{|c|c|c|c|c|}
\hline & \multicolumn{4}{|c|}{ Water regime } \\
\hline & Genotype & WW & $\mathrm{MD}$ & SD \\
\hline \multirow{3}{*}{$\begin{array}{l}\text { Neoxanthin } \\
\qquad\left(\mathrm{mg} \mathrm{g}^{-1} \mathrm{DW}\right)\end{array}$} & A55 & $0.476 \pm 0.014 \mathrm{aA}$ & $0.457 \pm 0.008 \mathrm{aA}$ & $0.539 \pm 0.045 \mathrm{aA}$ \\
\hline & A80 & $0.310 \pm 0.021 \mathrm{aB}$ & $0.388 \pm 0.047 \mathrm{aA}$ & $0.350 \pm 0.041 \mathrm{aB}$ \\
\hline & A116 & $0.365 \pm 0.030 \mathrm{aB}$ & $0.446 \pm 0.022 \mathrm{aA}$ & $0.409 \pm 0.022 \mathrm{aB}$ \\
\hline \multirow{3}{*}{$\begin{array}{l}\text { Violaxanthin (V) } \\
\qquad\left(\mathrm{mg} \mathrm{g}^{-1} \mathrm{DW}\right)\end{array}$} & A55 & $0.408 \pm 0.021 \mathrm{aA}$ & $0.171 \pm 0.022 \mathrm{cA}$ & $0.311 \pm 0.014 \mathrm{bA}$ \\
\hline & A80 & $0.278 \pm 0.016 \mathrm{aB}$ & $0.122 \pm 0.021 \mathrm{bA}$ & $0.221 \pm 0.063 \mathrm{aB}$ \\
\hline & A116 & $0.306 \pm 0.032 \mathrm{aB}$ & $0.121 \pm 0.012 \mathrm{bA}$ & $0.187 \pm 0.028 \mathrm{bB}$ \\
\hline \multirow{3}{*}{$\begin{array}{l}\text { Antheraxanthin (A) } \\
\qquad\left(\mathrm{mg} \mathrm{g}^{-1} \mathrm{DW}\right)\end{array}$} & A55 & $0.052 \pm 0.006 \mathrm{bA}$ & $0.036 \pm 0.006 \mathrm{bA}$ & $0.087 \pm 0.005 \mathrm{aA}$ \\
\hline & A80 & $0.040 \pm 0.004 \mathrm{abA}$ & $0.032 \pm 0.008 \mathrm{bA}$ & $0.064 \pm 0.019 \mathrm{aAB}$ \\
\hline & A116 & $0.051 \pm 0.014 \mathrm{aA}$ & $0.023 \pm 0.005 \mathrm{bA}$ & $0.050 \pm 0.008 \mathrm{aB}$ \\
\hline \multirow{3}{*}{$\begin{array}{l}\text { Zeaxanthin (Z) } \\
\qquad\left(\mathrm{mg} \mathrm{g}^{-1} \mathrm{DW}\right)\end{array}$} & A55 & $0.040 \pm 0.024 \mathrm{cA}$ & $0.530 \pm 0.032 \mathrm{aA}$ & $0.373 \pm 0.077 \mathrm{bA}$ \\
\hline & A80 & $0.017 \pm 0.004 \mathrm{bA}$ & $0.456 \pm 0.077 \mathrm{aA}$ & $0.340 \pm 0.006 \mathrm{aA}$ \\
\hline & A116 & $0.119 \pm 0.018 \mathrm{bA}$ & $0.424 \pm 0.031 \mathrm{aA}$ & $0.386 \pm 0.082 \mathrm{aA}$ \\
\hline \multirow{3}{*}{$\begin{array}{l}\mathrm{V}+\mathrm{A}+\mathrm{Z} \\
\quad\left(\mathrm{mg} \mathrm{g}^{-1} \mathrm{DW}\right)\end{array}$} & A55 & $0.500 \pm 0.041 \mathrm{bA}$ & $0.737 \pm 0.045 \mathrm{aA}$ & $0.771 \pm 0.068 \mathrm{aA}$ \\
\hline & A80 & $0.335 \pm 0.021 \mathrm{bB}$ & $0.610 \pm 0.080 \mathrm{aAB}$ & $0.625 \pm 0.082 \mathrm{aA}$ \\
\hline & A116 & $0.477 \pm 0.057 \mathrm{aAB}$ & $0.568 \pm 0.042 \mathrm{aB}$ & $0.623 \pm 0.049 \mathrm{aA}$ \\
\hline \multirow{3}{*}{$\begin{array}{l}\text { Lutein } \\
\qquad\left(\mathrm{mg} \mathrm{g}^{-1} \mathrm{DW}\right)\end{array}$} & A55 & $1.340 \pm 0.025 \mathrm{bA}$ & $1.750 \pm 0.018 \mathrm{aA}$ & $1.829 \pm 0.171 \mathrm{aA}$ \\
\hline & A80 & $0.930 \pm 0.064 \mathrm{bB}$ & $1.237 \pm 0.139 \mathrm{aB}$ & $1.269 \pm 0.157 \mathrm{aB}$ \\
\hline & A116 & $1.066 \pm 0.061 \mathrm{bAB}$ & $1.519 \pm 0.091 \mathrm{aAB}$ & $1.546 \pm 0.074 \mathrm{aAB}$ \\
\hline \multirow{3}{*}{$\begin{array}{l}\text { DEPS } \\
\qquad\left(\mathrm{mg} \mathrm{g}^{-1} \mathrm{DW}\right)\end{array}$} & A55 & $0.120 \pm 0.031 \mathrm{cB}$ & $0.747 \pm 0.029 \mathrm{aA}$ & $0.516 \pm 0.060 \mathrm{bA}$ \\
\hline & A80 & $0.109 \pm 0.006 \mathrm{cB}$ & $0.767 \pm 0.039 \mathrm{aA}$ & $0.638 \pm 0.066 \mathrm{bA}$ \\
\hline & A116 & $0.301 \pm 0.030 \mathrm{cA}$ & $0.768 \pm 0.016 \mathrm{aA}$ & $0.631 \pm 0.078 \mathrm{bA}$ \\
\hline \multirow{3}{*}{$\begin{array}{l}\alpha \text {-Carotene } \\
\qquad\left(\mathrm{mg} \mathrm{g}^{-1} \mathrm{DW}\right)\end{array}$} & A55 & $0.370 \pm 0.044 \mathrm{aA}$ & $0.439 \pm 0.017 \mathrm{aA}$ & $0.423 \pm 0.031 \mathrm{aA}$ \\
\hline & A80 & $0.290 \pm 0.015 \mathrm{bA}$ & $0.383 \pm 0.017 \mathrm{aAB}$ & $0.391 \pm 0.028 \mathrm{aA}$ \\
\hline & A116 & $0.202 \pm 0.027 \mathrm{bB}$ & $0.314 \pm 0.018 \mathrm{aB}$ & $0.376 \pm 0.031 \mathrm{aA}$ \\
\hline \multirow{3}{*}{$\begin{array}{l}\beta \text {-Carotene } \\
\qquad\left(\mathrm{mg} \mathrm{g}^{-1} \mathrm{DW}\right)\end{array}$} & A55 & $0.092 \pm 0.005 \mathrm{aA}$ & $0.089 \pm 0.002 \mathrm{aA}$ & $0.096 \pm 0.014 \mathrm{aA}$ \\
\hline & A80 & $0.061 \pm 0.002 \mathrm{bB}$ & $0.084 \pm 0.006 \mathrm{aA}$ & $0.061 \pm 0.006 \mathrm{bB}$ \\
\hline & A116 & $0.059 \pm 0.004 \mathrm{bB}$ & $0.088 \pm 0.006 \mathrm{aA}$ & $0.079 \pm 0.004 \mathrm{aAB}$ \\
\hline \multirow{3}{*}{$\begin{array}{r}(\alpha+\beta) \text { Carotene } \\
\left(\mathrm{mg} \mathrm{g}^{-1} \mathrm{DW}\right)\end{array}$} & A55 & $0.463 \pm 0.049 \mathrm{aA}$ & $0.528 \pm 0.016 \mathrm{aA}$ & $0.519 \pm 0.043 \mathrm{aA}$ \\
\hline & A80 & $0.351 \pm 0.014 \mathrm{bB}$ & $0.467 \pm 0.023 \mathrm{aAB}$ & $0.453 \pm 0.034 \mathrm{aA}$ \\
\hline & A116 & $0.260 \pm 0.030 \mathrm{bC}$ & $0.403 \pm 0.023 \mathrm{aB}$ & $0.455 \pm 0.029 \mathrm{aA}$ \\
\hline \multirow{3}{*}{$\begin{array}{l}(\alpha / \beta) \text { Carotene } \\
\left(\mathrm{g} \mathrm{g}^{-1}\right)\end{array}$} & A55 & $3.962 \pm 0.263 \mathrm{aAB}$ & $4.951 \pm 0.264 \mathrm{aA}$ & $4.817 \pm 0.609 \mathrm{aB}$ \\
\hline & A80 & $4.836 \pm 0.375 \mathrm{bA}$ & $4.664 \pm 0.237 \mathrm{bA}$ & $6.489 \pm 0.315 \mathrm{aA}$ \\
\hline & A116 & $3.383 \pm 0.326 \mathrm{aB}$ & $3.608 \pm 0.234 \mathrm{aB}$ & $4.859 \pm 0.507 \mathrm{bB}$ \\
\hline \multirow{3}{*}{$\begin{array}{l}\text { Total Carotenoids } \\
\qquad\left(\mathrm{mg} \mathrm{g}^{-1} \mathrm{DW}\right)\end{array}$} & A55 & $2.779 \pm 0.086 \mathrm{bA}$ & $3.471 \pm 0.077 \mathrm{aA}$ & $3.658 \pm 0.266 \mathrm{aA}$ \\
\hline & A80 & $1.926 \pm 0.113 \mathrm{bB}$ & $2.702 \pm 0.268 \mathrm{aB}$ & $2.697 \pm 0.308 \mathrm{aB}$ \\
\hline & A116 & $2.168 \pm 0.155 \mathrm{bB}$ & $2.935 \pm 0.153 \mathrm{aAB}$ & $3.032 \pm 0.171 \mathrm{aAB}$ \\
\hline \multirow{3}{*}{$\begin{array}{l}(\mathrm{V}+\mathrm{A}+\mathrm{Z}) / \text { Total Carotenoids } \\
\quad\left(\mathrm{g} \mathrm{g}^{-1}\right)\end{array}$} & A55 & $0.179 \pm 0.011 \mathrm{bB}$ & $0.211 \pm 0.008 \mathrm{aA}$ & $0.215 \pm 0.021 \mathrm{aA}$ \\
\hline & A80 & $0.174 \pm 0.007 \mathrm{bB}$ & $0.224 \pm 0.013 \mathrm{aA}$ & $0.230 \pm 0.010 \mathrm{aA}$ \\
\hline & A116 & $0.216 \pm 0.010 \mathrm{aA}$ & $0.193 \pm 0.005 \mathrm{aA}$ & $0.204 \pm 0.005 \mathrm{aA}$ \\
\hline
\end{tabular}

only for A80 and A116. Only A116 plants simultaneously presented a significant $\beta$-carotene increase (34\%), and the greatest rises in the ( $\alpha$ $+\beta$ )-carotene content $(75 \%)$, in the $(\alpha / \beta)$-carotene ratio (44\%), and in their weight among total carotenoids.

\subsection{Ribulose-1,5-bisphosphate carboxylase/oxygenase activities}

The carboxylation activity of RuBisCO showed some differences between landraces under WW conditions. A55 and A116 presented the highest initial and total activities (Fig. 3 A,B), respectively, whereas A55 and A80 presented the higher activation state (Fig. 3C). Furthermore, A80 showed the lowest values in both initial and total RuBisCO activities.

Despite some variations with the increasing water constraints, A55 plants were not negatively affected by drought in none of these RuBisCO parameters, thus suggesting that this landrace drought sensitivity was unrelated to RuBisCO, which in turn revealed a relevant resilience to the imposed conditions. Furthermore, strong initial and total activities rises (160 and $179 \%$, respectively) were found under MD in the A80 plants, and under SD conditions these activity values were still above those found in WW plants.

The A116 plants displayed a somewhat different pattern of variation than the plants of the other two landraces. No impact was observed in initial activity, but a clear gradual reduction of total activity (which reflects the amount of enzyme) was found in MD and SD plants, with the latter ones showing only $23 \%$ of the total activity of their WW plants. These trends in initial and total activities implicated a significant increase of 5.8 fold in the activation state value.

\subsection{GC-TOF-MS primary metabolite profiling}

The GC-TOF-MS analysis identified 32 primary metabolites, which included 14 amino acids and derivatives, six organic acids, 11 sugars and urea, whose relative levels varied across water deficit severity for these landraces (Fig. 4, Suppl. Table S1). Some primary metabolites were significantly affected by water deficit in the three landraces (proline, isoleucine, rhamnose and raffinose), but genotype differences were also observed in response to drought, both in MD and SD.

A116 MD and SD plants showed close variations, whereas in A55 and A80 plants the changes in metabolite levels were more influenced by drought severity (e.g., metabolite changes in A55 SD were closer to the ones of A80 SD than to those observed in A55 MD). Under MD conditions, A116 showed significant increases of amino acids proline, and threonine, as well as of putrescine, whereas under SD conditions 

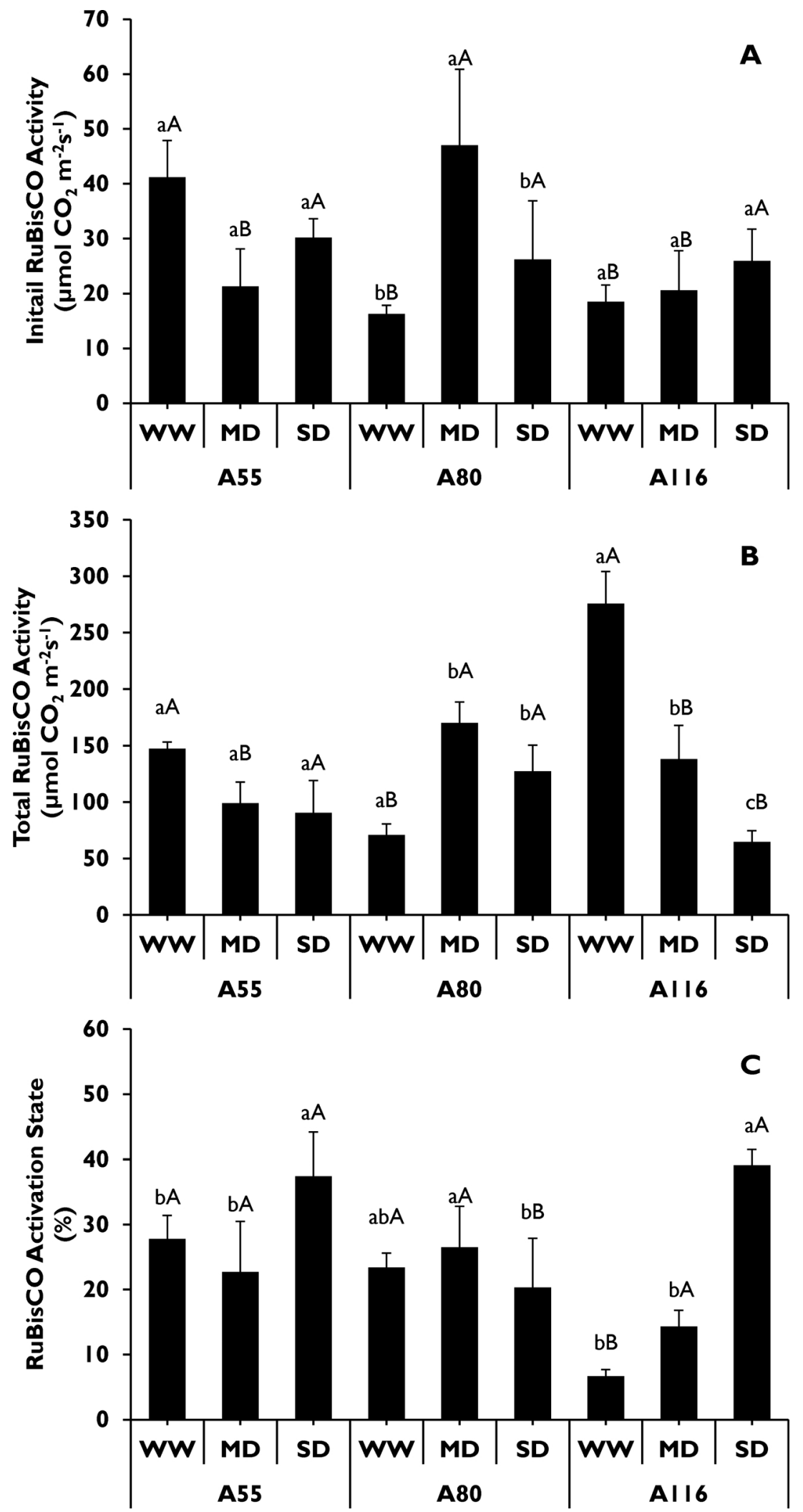

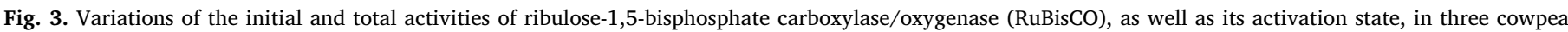

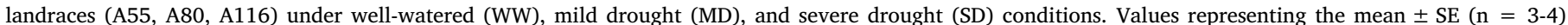

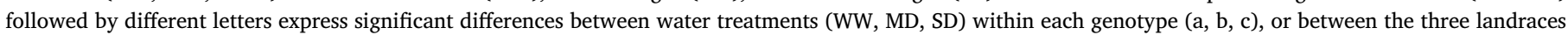
(A55, A80, A116) within each water condition (A, B, C). 

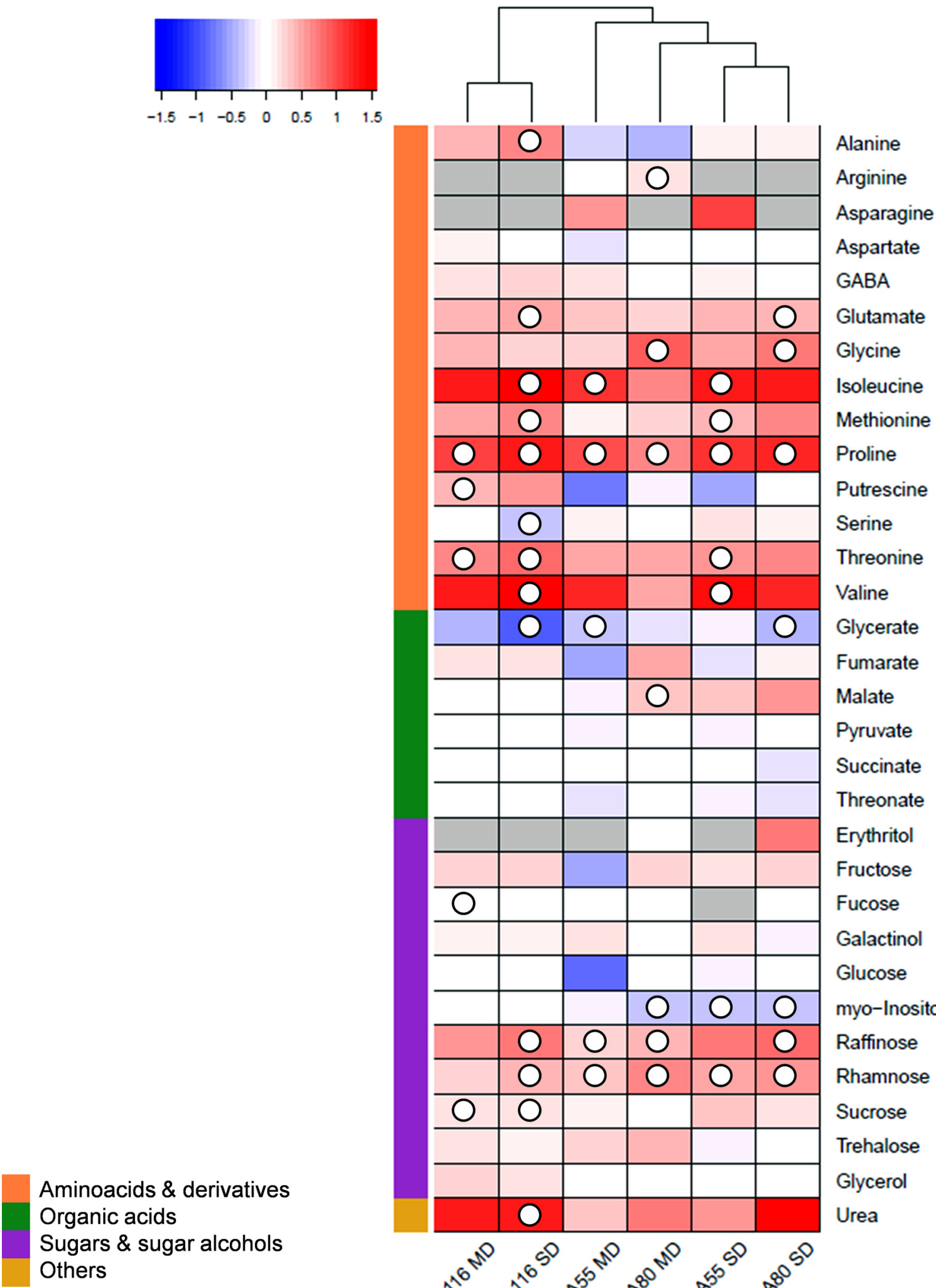

Glutamate

Glycine

Isoleucine

Methionine

Proline

Putrescine

Serine

Threonine

Valine

Glycerate

Fumarate

Malate

Pyruvate

Succinate

Threonate

Erythritol

Fructose

Fucose

Galactinol

Glucose

myo-Inositol

Raffinose

Rhamnose

Sucrose

Trehalose

Glycerol

Urea

Sugars \& sugar alcohols

Fig. 4. Heatmap showing metabolite responses in cowpea landraces under different water deficit conditions. Metabolites were determined as described in Section "Material and Methods." Relative values are normalized to the internal standard (ribitol) and fresh weight (FW) of the samples. Values presented as means \pm SE of three independent measurements. Dots indicate that the differences are statistically significant by Student's $t$-test $(p<0.05)$. Gray color squares represent not detected (n.d.) values. False-color imaging was performed on log10-transformed GC-TOF-MS data. AA, amino acids; OA, organic acids; S, sugars; SA, sugar alcohols.

seven amino acids were significantly increased (alanine, glutamate, methionine, proline, threonine and two branched-chain amino acids (BCAAs) isoleucine and valine), with emphasis on proline, isoleucine and valine (1.25-1.5 fold higher values, Fig. 4; 18-37 fold higher relative values, Suppl. Table S1). By contrast, a significant decline was observed in serine levels. In general, the levels of organic acids 
remained mostly unchanged in A116 either in MD or SD conditions, with the exception of glycerate whose levels were greatly reduced under SD conditions. In relation to sugars, only a few compounds showed significant increases: fucose and sucrose in MD plants; raffinose, rhamnose and sucrose in SD plants. Urea content was also significantly increased in A116 SD plants.

In A55 plants, the MD conditions significantly increased the isoleucine and proline levels. Glycerate was the only organic acid that registered a significant variation (reduction) under these conditions. Among sugar and sugar alcohols, only raffinose and rhamnose significantly increased. Under SD conditions, A55 plants presented a significant accumulation of a higher number of amino acids (methionine, proline, threonine, and BCAAs isoleucine and valine), whereas among sugars, only rhamnose (increase) and myo-inositol (decrease) were significantly altered. No significant variations were observed in organic acids.

In general, metabolite levels in A80 plants showed similar significant variations under both drought levels, namely as regards the amino acids glutamate, glycine and proline (increase), and sugars myoinositol (decrease), and raffinose and rhamnose (increase). For organic acids, significant variation was observed only in malate (increased in $\mathrm{MD}$ ), and glycerate (reduced in SD).

A metabolite pathway map (Fig. 5) to predict sites of metabolic regulation revealed that 17 of the detected metabolites were directly involved in the glycolysis, and in the tricarboxylic acid (TCA) cycle. However, differences between landraces were observed in the pool size of these metabolites, upon increased drought severity conditions, with A116 and A55 plants showing the highest (14) and lowest (8) number of significantly altered metabolites involved in these two pathways. The TCA cycle intermediates citrate, malate and fumarate remained unchanged after water deficit imposition in all landraces, except in A80 were malate levels increased (MD).
Metabolite analysis also revealed that the concentration of isoleucine and valine, two of the three critical BCAA's (leucine, isoleucine and valine), responsible for the supply of alternative electrons and substract for the plant respiration chain under stress conditions, significantly increased in A55 and A116 plants under SD conditions. Conversely, in A80 plants no significant variation of the BCAA's was observed.

Two urea cycle intermediary metabolites ornithine and arginine were detected, but showed no significant variation under MD or SD conditions in all landraces, except in A80 were arginine levels were significantly increased under MD conditions. In addition, methionine, a key metabolite of the methionine pathway were significantly increased in A55 and A116 SD plants, but remained unchanged in A80 ones. Two intermediary metabolites of the glutathione metabolism pathway were detected, proline and glutamate. However, no inter-genotypic differences were observed in proline values, which increased in either drought conditions in all landraces. Contrarily to proline, glutamate was unresponsive to MD in all landraces, but increased in A80 and A116 SD plants (Fig. 4,5).

The principal component analysis (PCA) (Fig. 6A), and the loading plot of metabolic profiles (Fig. 6B) in leaf tissues of A55, A80 and A116 plants, exposed to contrasting water availabilities, revealed that $55 \%$ of the observed variance was explained by the first two principal components, PC1 (39 \%) and PC2 (16 \%) (Fig. 6A). No visible inter-genotypic separation was highlighted, but segregation between WW and droughted plants was found, clearer in A55 and A116. The PCA results also revealed some level of variability between plant samples regarding metabolite levels, as reflected by their dispersion across quadrants in the PCA representation (Fig. 6A). The loadings plot, revealed a high number of metabolites in PC1 + , where a strong positive correlation between valine, isoleucine, proline, threonine and methionine is visible through their close proximity in the dimensional space (Fig. 6B). The

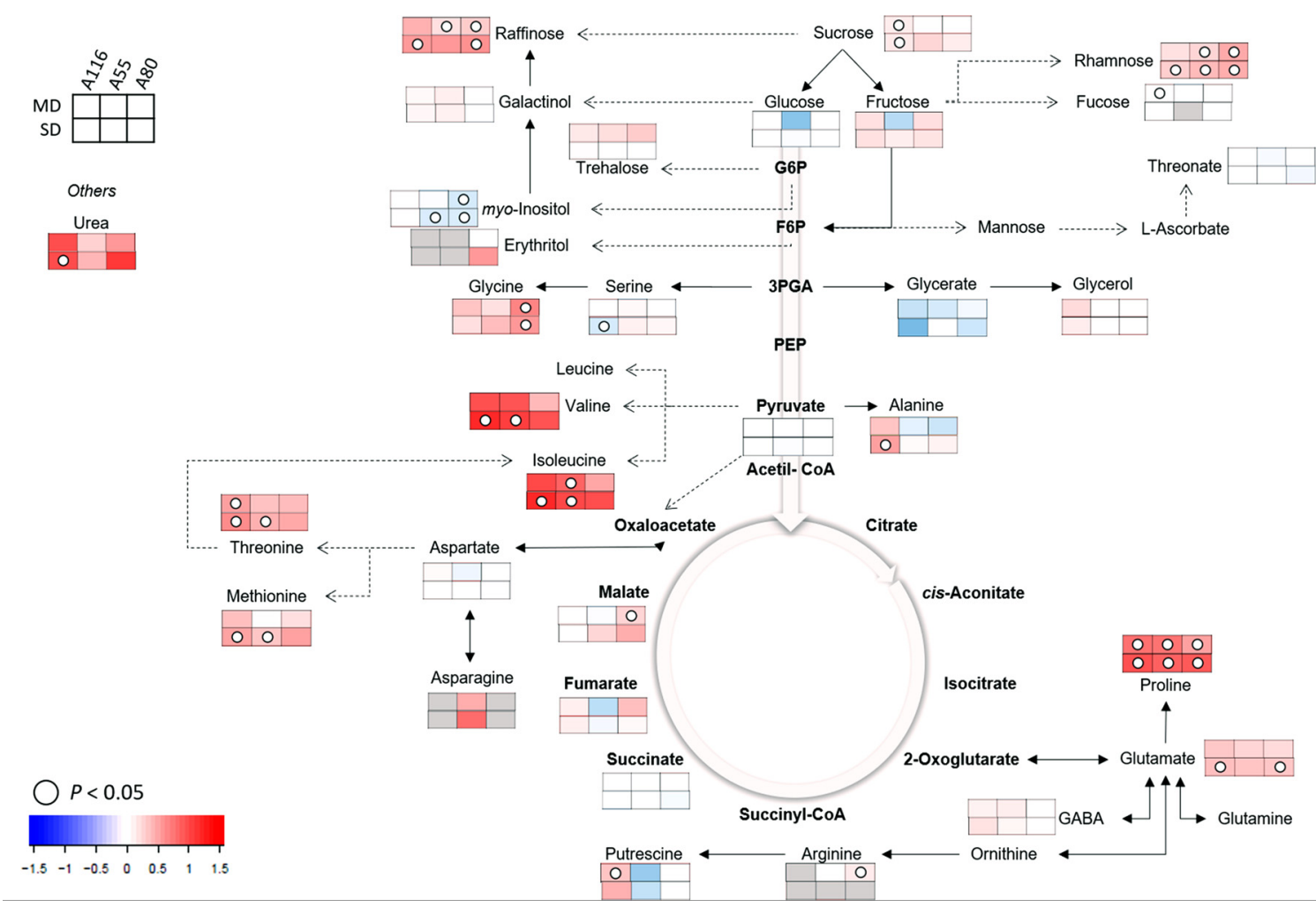

Fig. 5. Primary metabolic pathway reflecting the metabolite changes in three central Mozambican cowpea landraces (A55, A80 and A116), submitted to mild (MD) and severe (SD) water deficit and compared with well-watered (WW) control condition. Relative values (as means of three independent measurements) were normalized to the internal standard (ribitol) and fresh weight of the samples; false color imaging was performed on log10-transformed GC-TOF-MS metabolite data. Significant changes using Student's $t$-test are indicated as $p<0.05$, with respect to controls. 

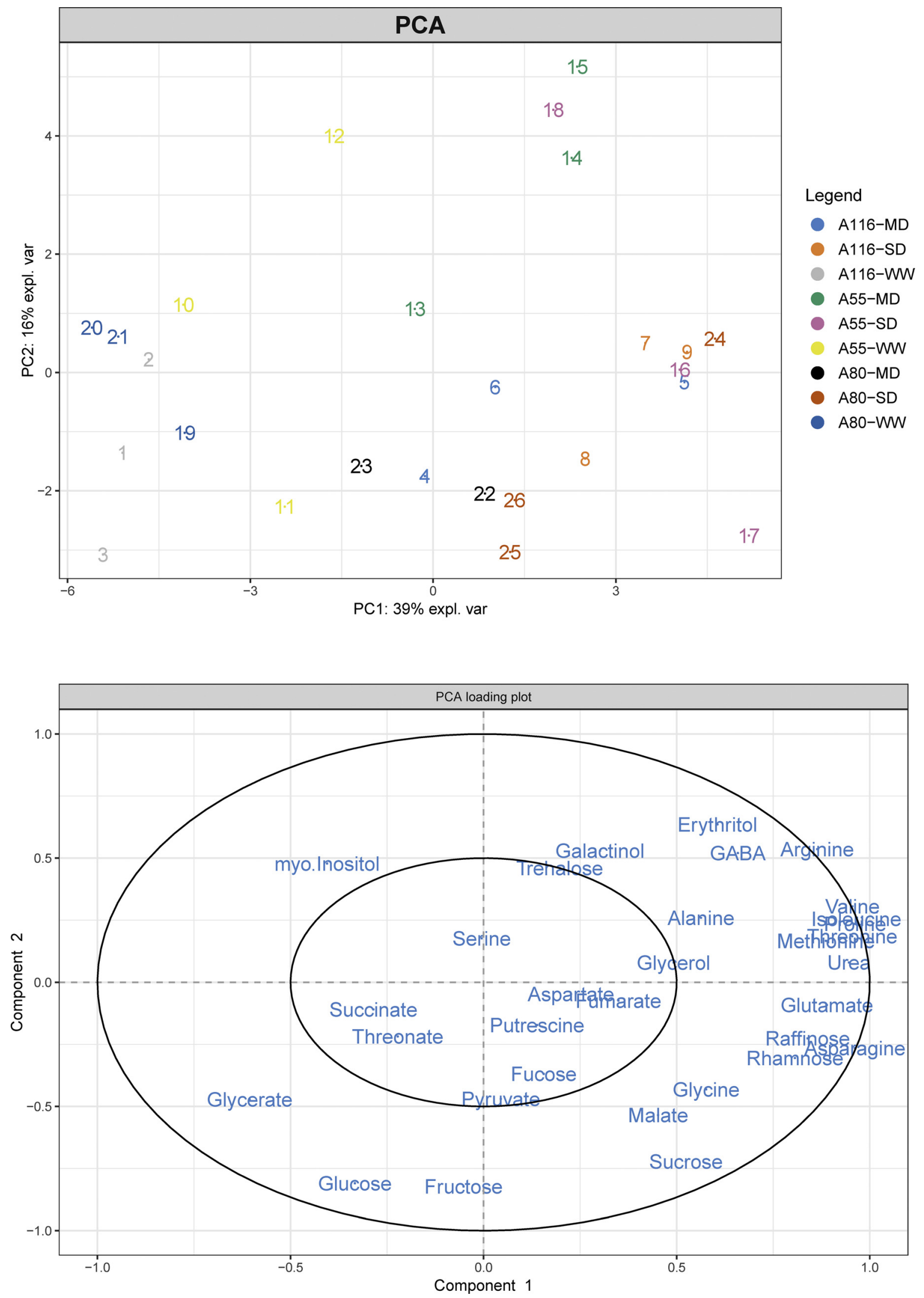

Fig. 6. Principal component analysis (PCA) score and loading plot of metabolic profiles in cowpea leaf tissues (A55, A80 and A116), submitted to the contrasting watering regimes well-watered (WW), mild water deficit (MD) and severe water deficit (SD). 
same trend was observed for raffinose, rhamnose and asparagine. The position of these two small clusters of highly correlated metabolites coupled with arginine and urea in the dimensional space reveals the bigger contribution they have to PCI total variance. In contrast, centrally located metabolites (serine, aspartate, fumarate, succinate, threonate, putrescine, fucose and pyruvate) had a low contribute to the observed variance. Glycerate, glucose and fructose, which are located in PC2-, are negatively correlated with PC1 + metabolites, meaning that their presence was inversely related with that of PC1 + metabolites.

To further explore and identify potential water-deficit responsive metabolites in cowpea, a partial least square discrimination analysis (PLS-DA) was performed (Fig. 7), aiming at to find the components or latent variables that discriminate as much as possible the group samples according to their maximum covariance, based on a genotype $\mathrm{x}$ water regime interaction. The PLS-DA model was validated based on the lowest classification error rate approach using the leave-one-out crossvalidation embedded in R package "mixOmics". The PLS-DA analysis clearly separated WW and droughted plants from the three landraces (Fig. 7A). Nine distinct sample groups were established, which can be grouped in three highly correlated and overlapping sub-clusters based on their location in the dimension space of the PLS-DA score. The first three groups were placed in the positive quadrant of the PLS-DA score plot, and represented the WW plants of A55, A80 and A116. Two other sample groups were related with A55 MD and SD plants, with the majority located in the interception between $y+$ and $x$ - axis respectively. Finally, four sample groups were found in the negative quadrant of the PLS-DA score plot, and overlap the droughted samples (MD and SD) of A80 and A116 landraces.

The PLS-DA loading plots revealed that the metabolites that significantly increased in water deficit exposed plants, particularly in A116 MD, A116 SD, A80 MD and A80 SD that are located in the negative quadrant of the PLS-DA loadings plot (Fig. 7B). These metabolites where negatively correlated with myo-inositol that significantly increased in WW samples from A55 and A80 located in the positive quadrant of the PLS-DA score plot. The loadings plot also revealed that WW samples A116 had higher levels of glycerate, glucose, succinate and threonate.
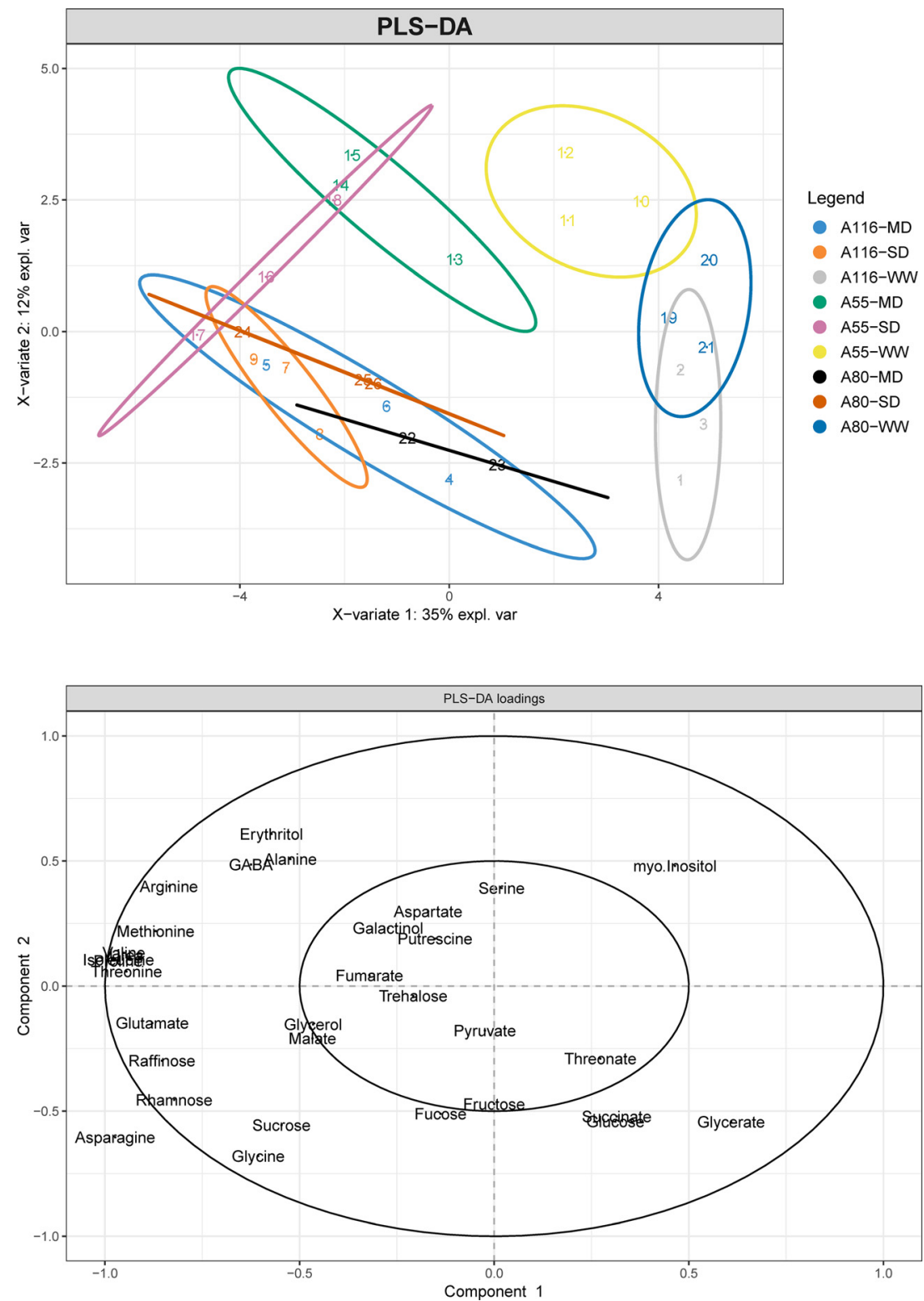

Fig. 7. Partial least square discrimination analysis (PLS-DA) score and loading plots of metabolic profiles in cowpea leaf tissues (A55, A80 and A116), submitted to the contrasting watering regimes well-watered (WW), mild water deficit (MD) and severe water deficit (SD). 


\section{Discussion}

\subsection{Plant responses at photosynthetic level}

The imposition of water restriction gradually reduced leaf water status (RWC) in all landraces, although somewhat differently across them (Fig. 1), in agreement with the genotype dependent decrease in RWC observed in Phaseolus vulgaris genotypes of contrasting drought tolerance when submitted to water deficit (Rosales et al., 2013). In fact, the plants of the drought tolerant landrace A116 maintained the highest RWC values under MD and SD conditions, and, therefore, a better water status (Fig. 1). By contrast, A55 plants showed the greatest RWC reductions under MD and SD conditions, what would agree with their higher drought sensitivity (Rosales et al., 2013; Zegaoui et al., 2017).

Physiological responses to water constraints dealing with photosynthetic performance (namely, leaf gas exchanges and Chl $a$ fluorescence parameters) have been widely explored to identify drought tolerant germplasm, namely in cowpea (Campos et al., 1999; Singh and Reddy, 2011; Rosales et al., 2012; Goufo et al., 2017), and other legumes, such as Phaseolus vulgaris L. (Rosales et al., 2013; Ramalho et al., 2014), Lupinus albus L. (Ramalho and Chaves, 1992), and Arachis hypogaea L. (Lauriano et al., 2004).

Here this analysis pointed for different drought tolerance levels among the studied cowpea landraces. The observed RWC changes were accompanied by reductions of $g_{s}$, and water loss through transpiration
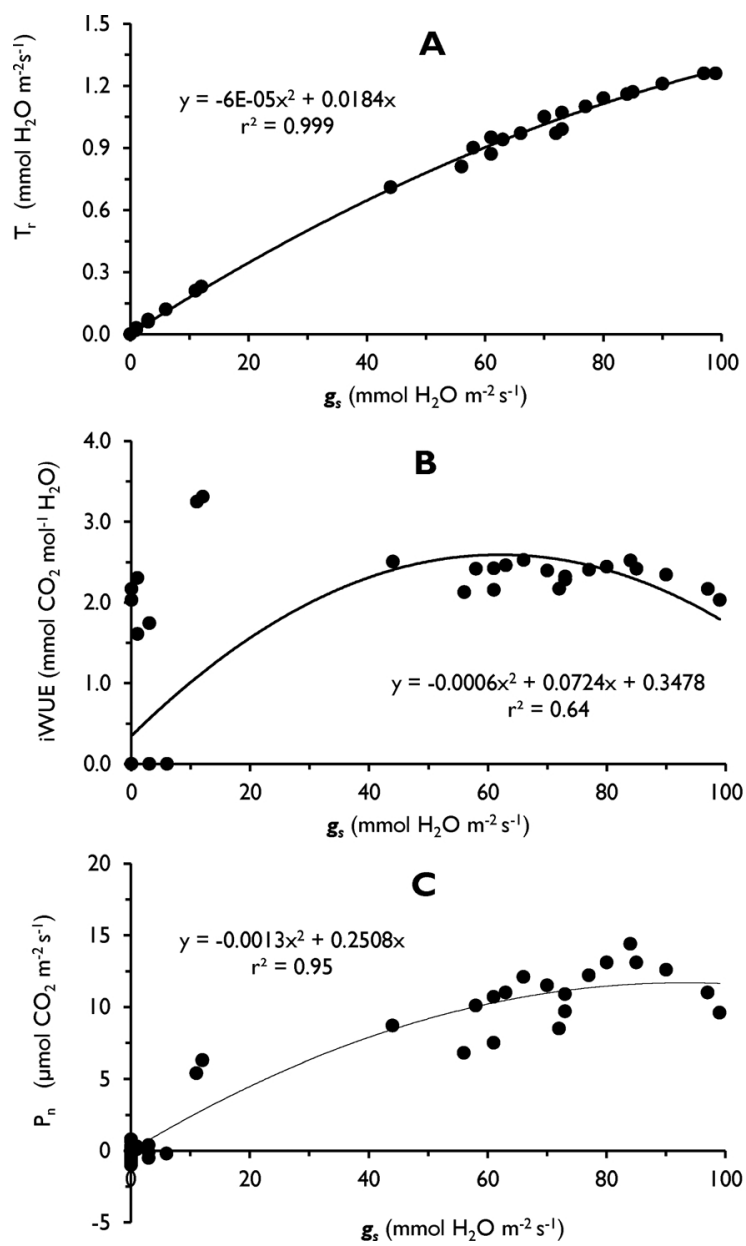

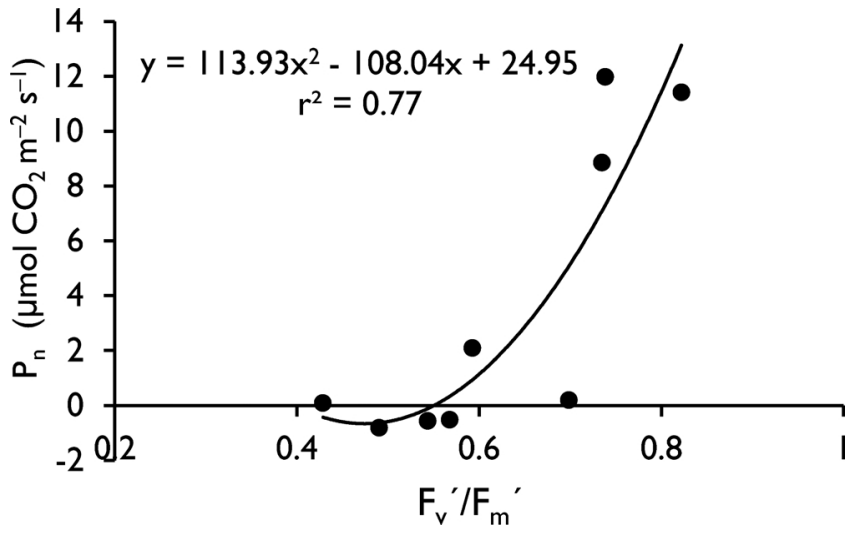

Fig. 9. Regression between net photosynthetic rate $\left(P_{n}\right)$ and the photochemical efficiency of PSII in light $\left(\mathrm{F}_{\mathrm{v}}\right.$ '/ $\mathrm{F}_{\mathrm{m}}$ '). Each point represent the mean values presented in Fig. $2\left(\mathrm{P}_{\mathrm{n}}\right)$ and Table $1\left(\mathrm{~F}_{\mathrm{v}}{ }^{\prime} / \mathrm{F}_{\mathrm{m}}\right)$, regarding the cowpea landraces (A55, A80 and A116), submitted to the contrasting watering regimes wellwatered (WW), mild water deficit (MD) and severe water deficit (SD).

( $\mathrm{T}_{\mathrm{r}}$ ) (Fig. 2), associated to a tight control of stomata aperture (Fig. 8A) that is a common response of most plants when exposed to water shortage, among them common bean (Karimzadeh-Soureshjani et al., 2019), sunflower (Tezara et al., 2002), and wheat (Li et al., 2017). Such reduced $\mathrm{g}_{\mathrm{s}}$ would have restricted $\mathrm{CO}_{2}$ access to the carboxylation sites
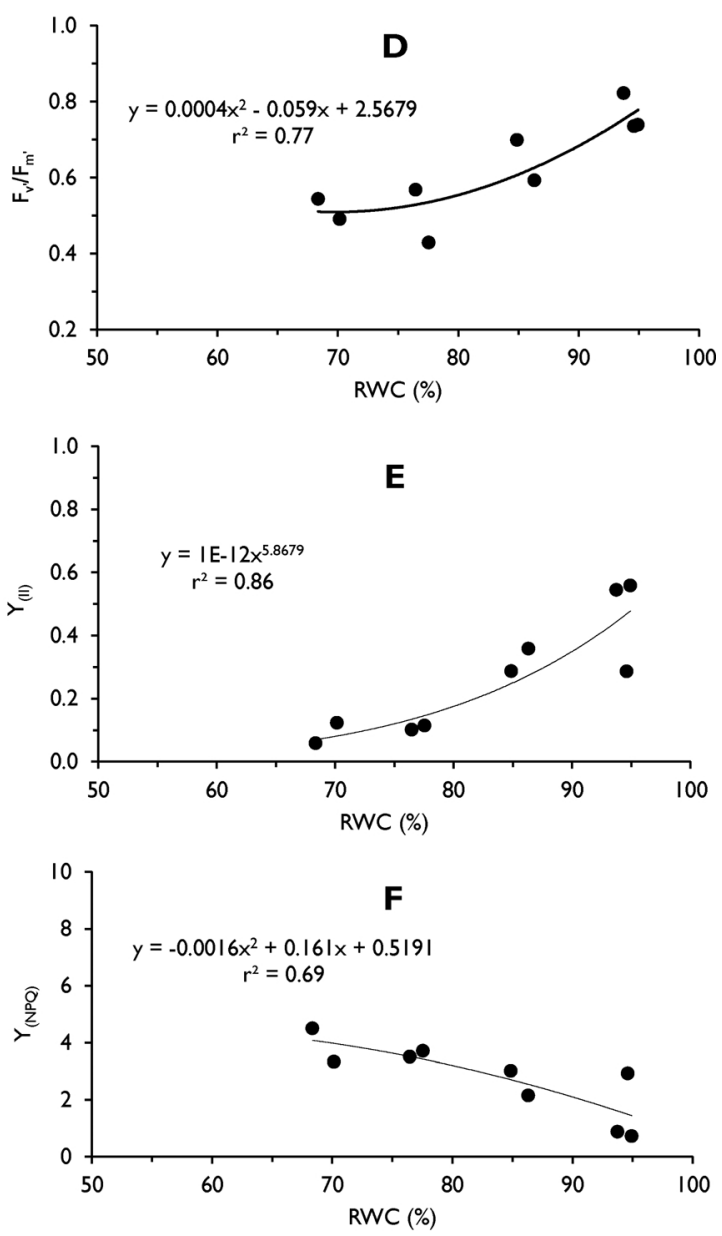

Fig. 8. Exploring functional relationship between the leaf gas exchange parameters net photosynthesis $\left(\mathrm{P}_{\mathrm{n}}\right)$, stomatal conductance to water vapor $\left(\mathrm{g}_{\mathrm{s}}\right)$, transpiration $\left(T_{r}\right)$, and the instantaneous water use efficiency (iWUE $\left.=P_{n} / T_{r}\right)(A, B, C)$, as well as between relative water content (RWC) and the chlorophyll a fluorescence parameters $\mathrm{F}_{\mathrm{v}}{ }^{\prime} / \mathrm{F}_{\mathrm{m}}{ }^{\prime}, \mathrm{Y}_{(\mathrm{II})}$, and $\mathrm{Y}_{(\mathrm{NPQ})}(\mathrm{D}, \mathrm{E}, \mathrm{F})$. Each point represent the mean values presented in Fig. 1 (RWC), Fig. 2 (gas exchange parameters) and Table 1 (chlorophyll a fluorescence parameters, as defined in Table 2 legend), regarding the cowpea landraces (A55, A80 and A116), submitted to the contrasting watering regimes well-watered (WW), mild water deficit (MD) and severe water deficit (SD). 
in the chloroplast, leading to strong $\mathrm{P}_{\mathrm{n}}$ declines in all landraces, and evincing a strong stomatal limitation of $\mathrm{P}_{\mathrm{n}}$ (Fig. 8C). However, differences between landraces emerged with the evaluation of $\mathrm{P}_{\text {nmax }}$ (under saturating $\mathrm{CO}_{2}$ conditions) (Fig. 2). Under MD conditions, A80 and, especially, A116 MD plants maintained relevant C-assimilation, whereas A55 did not, thus pointing to a higher sensitivity at non-stomatal (mesophyll) level. Still, in SD conditions, the impact at mesophyll level dominated the reduction of $\mathrm{P}_{\mathrm{n}}$ (and $\mathrm{P}_{\mathrm{nmax}}$ ) to negligible values, without differences between landraces.

Among the non-stomatal causes that might contribute to $\mathrm{P}_{\mathrm{n}}$ limitation is the impact in the PSII photochemical performance (Table 1, Fig. 9), even under moderate drought as reported in Phaseolus vulgaris L. landraces (Ramalho, et al. 2014). The somewhat lower sensitivity of the photosynthetic machinery potential $\left(\mathrm{P}_{\mathrm{nmax}}\right)$ under $\mathrm{MD}$ conditions in A116 than in A55 globally agreed with the Chl $a$ fluorescence results, which is a valuable non-destructive tool to assess drought impacts on PSII (White and Critchley, 1999). A116 (and partly A80) showed smaller impacts on the energy driven to photochemical events $\left(\mathrm{q}_{\mathrm{L}}\right)$ and to linear electron transport $\left(\mathrm{Y}_{(\mathrm{II})}\right)$, as compared with A55, which showed the minimal values among the three landraces in both MD and SD conditions. This also justified a higher need for energy dissipation in $A 55$, as reflected in the greater values of $\mathrm{Y}_{(\mathrm{NPQ})}$ and $\mathrm{q}_{\mathrm{N}}$, and also the stronger PSII inactivation status $\left(\mathrm{F}_{\mathrm{s}} / \mathrm{F}_{\mathrm{m}}{ }^{\prime}\right)$ among the three landraces. Therefore, contrasting drought tolerance levels in cowpea have in fact different photosynthetic responses, as reported for Mediterranean landraces (Goufo et al., 2017; Scotti-Campos et al., 2017). Nevertheless, even in A55 plants the non-regulated energy dissipation of PSII $\left(\mathrm{Y}_{(\mathrm{NO})}\right)$ did not increase under the harshest drought conditions (SD), and the chronic photoinhibition index ( $\mathrm{PI}_{\mathrm{Chr}}$ ) kept quite low values (Table 1). In fact, the reduction in $\mathrm{Y}_{(\mathrm{II})}$ in MD and SD plants of all landraces was fully compensated by an increase in non-photochemical energy dissipation mechanisms in PSII, related to the protective down-regulation of lightharvesting function $\left(\mathrm{Y}_{(\mathrm{NPQ})}\right)$, without an increase attributable to photoinactivation and non-regulated energy (heat and fluorescence) dissipation at PSII ( $\left.\mathrm{Y}_{(\mathrm{NO})}\right)$ (Huang et al., 2011; Rodrigues et al., 2016). Altogether, these results points out that all landraces showed some extent of drought tolerance and acclimation (as also reflected in the synthesis of photoprotective carotenoids), and that even the more drought sensitive A55 plants showed only moderate impacts at PSII functioning level.

Further exploring our results, it was possible to find positive correlations between RWC and $\mathrm{F}_{\mathrm{v}}{ }^{\prime} / \mathrm{F}_{\mathrm{m}}$ ', and $\mathrm{Y}_{(\mathrm{II})}$ (Fig. 8D,E). Since A116 showed higher RWC values in MD and SD conditions that the other landraces (particularly as compared with A55) that justifies the maintenance of higher efficiency on the use of light energy $\left(\mathrm{F}_{\mathrm{v}}{ }^{\prime} / \mathrm{F}_{\mathrm{m}}\right.$ ' and $\left.\mathrm{Y}_{(\mathrm{II})}\right)$. Additionally, the significant correlation of RWC with $\mathrm{Y}_{(\mathrm{NPQ})}$ (Fig. 8F) confirmed that the lower RWC values in A55 were related to the higher energy dissipation. In this context, the variations in RWC across water regimes, supported by ecophysiological data, such as Chl $a$ fluorescence analysis, can be used as a cost-effective method to prescreen local landraces and identify drought tolerant ecotypes (Osonubi, 1985; Kalaji et al., 2018). This is an important result particularly for Africa, where exist a wide cross-regional exchange of genetic materials.

The above referred higher need for energy dissipation in droughted A55 plants agreed the higher absolute contents of photoprotective/ dissipative pigments. In fact, A55 presented the higher contents of the xanthophyll pool size $(V+A+Z)$, zeaxanthin (except SD), both $\alpha$ - and $\beta$-carotenes, lutein and total carotenoids, although in most cases showing smaller increases (and a tendency to lower DEPS values) than the other landraces under similar drought conditions. This also highlighted that important pigment changes were commonly triggered at chloroplast level across landraces, as a photoprotective response to drought imposition, as frequently found in other plants where the photochemical use of energy is reduced, namely under water (Ramalho et al., 2014), temperature (Rodrigues et al., 2016; Ramalho et al., 2018), and salinity (Batista-Santos et al., 2015) stress conditions.
Photosynthetic machinery sensitivity to environmental constraints is also often related with RuBisCO (Chaves et al., 2003; Rodrigues et al., 2016). Kinetic traits can vary among RuBisCO forms, likely reflecting different environmental selective pressures during evolution (Iñiguez et al., 2020), and improvements in their overall catalytic performance through biotechnological approaches was suggested to constitute a way to significantly increase plant yield, especially under stressful environmental conditions (Parry et al., 2013; Lin et al., 2014). In fact, water deficit or heat frequently cause proteins denaturation (Hoekstra et al., 2001), decrease the synthesis of the small RuBisCO units, and increase RuBisCO inhibitors, thus affecting this enzyme activity (Vu et al., 1999; Galmés et al., 2013; Fahad et al., 2017). Furthermore, such reductions in RuBisCO activity are believed to constitute one of the main effects caused by climate change, and should be considered in prediction models on future plant productivity (Galmés et al., 2013). However, no direct relation was found between RWC and RuBisCO when all stress levels and landraces were plotted (data not shown). Moreover, A55 did not show clear significant changes regarding both initial and total RuBisCO activities, as well in the activation state (Fig. 3). Additionally, the more drought tolerant A116 plants showed a reduction in total activity, but not in the initial activity, thus increasing the RuBisCO activation state. Therefore, these cowpea landraces did not present a particular (and consistent) differential sensitivity of RuBisCO between landraces, associated to the imposed drought conditions. Instead, initial activity was not negatively affected in none of the three landraces, and was maintained well above $P_{n}$ values. This suggests that RuBisCO was not a major contributor to the non-stomatal limitation of $\mathrm{C}$-assimilation. This contrasted with the observations of major negative impacts on RuBisCO activity under a range of abiotic stresses (Galmés et al., 2013; Fahad et al., 2017), which are main drivers of negative impacts on crop productivity, since $\mathrm{CO}_{2}$ fixation by RuBisCO is the main source of assimilating atmospheric $\mathrm{CO}_{2}$ into organic carbon in the biosphere (Lin et al., 2014; Iñiguez et al., 2020). Yet, with the exception of total activity in A116, our findings agreed with the reports of unchanged initial RuBisCO activity under decreased RWC (Flexas et al., 2006), and unaffected RuBisCO contents in drought tolerant wheat varieties (Nagy et al., 2013), thus highlighting an interesting tolerance of RuBisCO to harsh drought conditions in cowpea landraces.

\subsection{Primary metabolite profiling in response to drought}

Metabolomics offers an opportunity to improve the efficiency of agricultural research and development (Tian et al., 2016a), namely in Africa's and regarding cowpea landraces. Plants alter their primary metabolite profile, as part of the acclimation to dehydration and to maintain redox homeostasis (Nagy et al., 2013; Mundim and Pringle, 2018). Metabolite profiling have been underutilized in Africa, particularly in Mozambique, with a recent exception where primary metabolite profiling was used to improve the understanding of adjustment mechanisms under different fire regimes in the Miombo and Mopane tree legumes species (Duvane et al., 2017).

Despite observed inter-genotypic variability, significant variation in proline levels under MD, and SD across all landraces was observed (Fig. 4, Suppl. Table S1). The same was observed with regards to rhamnose except in A116 under MD conditions. The increased level of proline is frequently associated to osmoregulation and increased resistance to water deficit (Hayat et al., 2012), what is also in line with amino acids responses in drought-tolerance wheat (Yadav et al., 2019). Similar increasing patterns were observed in all landraces for proline, valine, isoleucine (among amino acids), and rhamnose and raffinose (among sugars). Therefore, these metabolites can be a relevant part of a common cowpea response to drought, although they cannot be a used as proxy for drought tolerance screening. This could be the particular case of raffinose, which can have protective functions against desiccation upon cold, salinity, osmotic and water stresses (see Ramalho et al., 2014). In fact, under reduced water availability, chloroplast 
membranes can be stabilised by sugars and maintain thylakoid electron transport, with the trisaccharide raffinose being even more effective than the disaccharide sucrose (Santarius, 1973).

A closer look showed that A116 revealed the greatest accumulation of most responsive metabolites (13 in a total of 14) under either MD or SD. Furthermore, significant increases in sucrose, fucose, urea, alanine and putrescine were observed only in A116 plants (Fig. 4,5), suggesting that these metabolites could constitute drought tolerance probes, thus, deserving further studies to confirm this potential use. In fact, drought tolerant genotypes exposed to water deficit showed accumulation of sucrose in wheat (Marček et al., 2019), and fucose in sesame (You et al., 2019). Sucrose accumulation is often linked to osmotic adjustment, allowing the plant to maintain higher water content and stomatal conductance, thus allowing greater $\mathrm{P}_{\mathrm{n}}$ under drought conditions. In fact, the acquisition of tolerance to water deficit also relies on the ability to maintain osmotic homeostasis, preserving cell turgor through accumulation of compatible solutes, namely sugars (among them sucrose, glucose, fructose and raffinose family oligosaccharides, RFOs), sugar alcohols (namely, mannitol), and amino acids (e.g., proline, and glutamic acid), quaternary ammonium compounds (e.g., glycine, betaine and alanine betaine) (Chaves et al., 2003; Ramalho et al., 2014). Additionally, sugars are also known to have osmoprotective functions, linked to their hydrophilic structure, which allows them to replace water on protein surfaces, protein complexes or membranes, thus contributing to protect biological functions (Rejšková et al., 2007). Higher sucrose levels are also known to enhance mechanical strength of cell walls for minimizing water loss and cell dehydration, which are features crucial for plants to resist to and recover from drought (Wang et al., 2016). Furthermore, carbohydrates can also play an important role in hydroxyl radical scavenging, acting against oxidative stress, namely the RFOs (Rejšková et al., 2007).

Under SD conditions the A116 plants showed also increased putrescine levels, with a likely positive impact on the acclimation to water shortage. In fact, high putrescine levels were associated with increased amount of carotenoids (Zeid and Shedeed, 2006), to enhanced tolerance to dehydration, cold (Alet et al., 2011), and drought (Yang et al., 2007; Alcázar et al., 2010; Wu et al., 2016), and to increased cell growth and development under stress conditions (Gill and Tuteja, 2010).

Finally, the significant higher contents of urea reported A116-SD plants (partly in A80-SD) was in line with the accumulation observed in maize only under severe conditions of heat stress or combined heat and drought stresses, what might be determined by regulatory mechanisms specifically operating under these harsh conditions (Obata et al., 2015), since urea recycling seems to be quite important under stress exposure (Winter et al., 2015). On the contrary, A116-SD plants showed reduced serine levels, in opposition to the increase observed in tolerant wheat plants reported (Guo et al., 2018).

The use of statistical tools can strongly improve the information obtained from metabolomic data. A PLS-DA allowed a clear separation of the WW from the droughted (MD and SD) samples, for all three landraces (Fig. 7A). The PLS-DA further separated A55-MD and A55-SD groups, in relation both to their WW plants, and to the group comprising MD and SD samples of A116 and A80. This confirmed PLS-DA usefulness as a tool to better understand plant response to drought (Ullah et al., 2017; You et al., 2019), since it separated the droughted plants of the most sensitive genotype (A55) from its own control, and even from the droughted plants of the landraces with known moderate (A80) and high (A116) drought tolerance.

In detail, the loading plot shows that myo-inositol, glycerate, succinate and glucose were the metabolites that most contributed to the separation between WW from MD and SD samples. Erythritol, alanine and GABA were the metabolites that promoted to the separation of the A55 MD and SD samples from the remaining groups (Fig. 7B). The metabolites most responsible for the separation of the group comprising MD and SD samples of A116 and A80 were the branched-chain amino acids valine and isoleucine and the amino acids proline, threonine, methionine, arginine, glutamate, asparagine and sugars raffinose and rhamnose. The increased levels of arginine upon MD conditions might suggest an altered modulation of the nitrogen balance in A80, since arginine can be used as a nitrogen storage molecule, as well as a precursor of polyamines (as putrescine) and proline, both of which are known to be involved in plant stress response (Winter et al., 2015; Hasan et al., 2018).

Taken all results together, it was clear that the use of an ecophysiological characterization (particularly focused in the C-assimilatory pathway), together with a metabolomics profiling through GC-TOF-MS, coupled to a PLS-DA, constitute a successful approach to characterize and select drought tolerant cowpea landraces.

\section{Conclusions}

The presented results showed inter-genotypic variability to drought response and provided valuable information on the physiological and metabolic mechanisms underlying drought tolerance in central Mozambique cowpea landraces. A116 maintained a higher plant water status under drought, associated to the higher potential $\left(\mathrm{P}_{\text {nmax }}\right)$ photosynthesis under $\mathrm{MD}$, despite negligible values were observed in $\mathrm{SD}$ conditions in all landraces. A higher photosynthetic apparatus performance in A116 was also reflected in the greater proportion of energy driven to photochemical events $\left(\mathrm{q}_{\mathrm{L}}, \mathrm{Y}_{(\mathrm{II})}\right)$, and a lower need for photoprotective thermal dissipation mechanisms $\left(\mathrm{Y}_{(\mathrm{NPQ})}, \mathrm{q}_{\mathrm{N}}\right)$. Nevertheless, some acclimation response was observed in all landraces, with A55 showing the greater reinforcements regarding photoprotective mechanisms associated with high contents of zeaxanthin, lutein, and carotenes, as well as with $\mathrm{Y}_{(\mathrm{NPQ})}$, and $\mathrm{q}_{\mathrm{N}}$. Although PSII photoinactivation $\left(\mathrm{F}_{\mathrm{s}} / \mathrm{F}_{\mathrm{m}}\right)$ tended to higher values in droughted (both MD and SD) A55 plants, such acclimation responses explained the absence of uncontrolled non-regulated energy (heat and fluorescence) dissipation at PSII ( $\mathrm{Y}_{(\mathrm{NO})}$ did not rise), and that $\mathrm{PI}_{\mathrm{Chr}}$ was even lower in A55 than in the other landraces in SD plants. Notably, no negative impact was observed in the initial activity of RuBisCO in SD plants of all landraces, suggesting a high resilience to drought of this enzyme in cowpea, and that this enzyme was not a major non-stomatal limiting point to $\mathrm{C}$-assimilation.

Metabolite profiling, complemented with a PLS-DA, allowed a better separation of A116 from A55 plants according to their degree of drought tolerance. Primary metabolite profiling identified 32 compounds, 17 of which directly involved in glycolysis and tricarboxylic acid cycle. A116 showed the greatest accumulation of most responsive metabolites (13 in a total of 14) under either MD or SD conditions, and was the only one to show accumulation of sucrose, fucose, alanine, putrescine and urea. This points these metabolites as good candidates to be used as drought tolerance probes, therefore deserving further studies to confirm this potential. Other compounds, as proline, valine, isoleucine (among amino acids), and rhamnose and raffinose (among sugars) showed close increase patterns across landraces, and although they did not differentiate the tolerance degree they would have relevant roles in the common drought response of cowpea plants, which include as well the increase in photoprotective carotenoids. Therefore, the establishment of a primary metabolite profiling (sugars, amino and organic acids) through GC-TOF-MS followed by a PLS-DA can constitute a successful strategy to improve our understanding of how and to which extent cowpea metabolism respond under drought conditions.

In conclusion, this study highlights the advantages of an in-depth and integrated throughput and targeted study (focused in the C-assimilation pathway), characterizing the physiological (leaf gas exchange, photosynthetic pigments, Chl $a$ fluorescence) and biochemical (RuBisCO activity, and GC-TOF-MS primary metabolite profiling coupled to a PLS-DA) plant responses to support the identification and selection of drought tolerant cowpea landraces. This is a pioneer approach as regards the characterization of Africa's and central Mozambique highly diverse cowpea germplasm, and constitutes a first 
step towards a breeding strategy aiming at obtain high yield, and drought tolerant elite varieties.

\section{Author contributions}

According to their competences, all authors contributed transversally to the several stages of the work, including its design, data acquisition, analysis and interpretation, critically review of the manuscript, and approval of the submitted version. Furthermore, they agree to be accountable for all aspects of the work in ensuring that questions related to the accuracy or integrity of any part of the work were appropriately investigated and resolved.

\section{Funding}

This work was supported by, supported by funds from the Mozambican Fundo Nacional de Investigação (Project 201-Inv-FNI), by NUFFIC, the Netherlands (Project NICHE-Moz-151), and by Fundação para a Ciência e a Tecnologia, I.P., Portugal, through the PhD fellowship SFRH/BD/113952/2015 (A. Gomes), and the research units UID/ 04129/2020 (LEAF), UIDP/04035/2020 (GeoBioTec), and UIDB/ 00239/2020 (CEF).

\section{Declaration of Competing Interest}

The authors declare that there are not any potential conflicts of interest.

\section{Acknowledgements}

The authors would like to thank Tech. Paula Alves for technical assistance.

\section{Appendix A. Supplementary data}

Supplementary material related to this article can be found, in the online version, at doi:https://doi.org/10.1016/j.envexpbot.2020. 104060 .

\section{References}

Adams III, W.W., Demmig-Adams, B., 2004. Chlorophyll fluorescence as a tool to monitor plant response to the environment. In: Papageorgiou, G.C., Govindjee (Eds.), Chlorophyll a Fluorescence: A Probe of Photosynthesis. Chapter 22. Advances in Photosynthesis and Respiration Series. Springer, pp. 583-604. https://doi.org/10. 1007/978-1-4020-3218-9.

Alcázar, R., Planas, J., Saxena, T., Zarza, X., Bortolotti, C., Cuevas, J., Bitrián, M., Tiburcio, A.F., Altabella, T., 2010. Putrescine accumulation confers drought tolerance in transgenic arabidopsis plants over-expressing the homologous arginine decarboxylase 2 gene. Plant Physiol. Biochem. 48, 547-552. https://doi.org/10.1016/j. plaphy.2010.02.002.

Alet, A.I., Sanchez, D.H., Cuevas, J.C., Del Valle, S., Altabella, T., Tiburcio, A.F., Marco, F., Ferrando, A., Espasandín, F.D., González, M.E., Ruiz, O.A., Carrasco, P.P., 2011. Putrescine accumulation in Arabidopsis thaliana transgenic lines enhances tolerance to dehydration and freezing stress. Plant Signal. Behav. 6 (2), 278-286. https://doi. org/10.4161/psb.6.2.14702.

Asai, T., Matsukawa, T., Kajiyama, S., 2017. Metabolomic analysis of primary metabolites in citrus leaf during defense responses. J. Biosci. Bioeng. 123 (3), 376-381. https:// doi.org/10.1016/j.jbiosc.2016.09.013.

Batista-Santos, P., Duro, N., Rodrigues, A.P., Semedo, J.N., Alves, P., da Costa, M., Graça, I., Pais, I.P., Scotti-Campos, P., Lidon, F.C., Leitão, A.E., Pawlowski, K., RibeiroBarros, A.I., Ramalho, J.C., 2015. Is salt stress tolerance in Casuarina glauca Sieb. Ex Spreng. associated with its nitrogen-fixing root-nodule symbiosis? An analysis at the photosynthetic level. Plant Physiol. Biochem. 96, 97-109. https://doi.org/10.1016/j. plaphy.2015.07.021.

Blum, A., 2009. Effective use of water (EUW) and not water-use efficiency (WUE) is the target of crop yield improvement under drought stress. Field Crops Res. 112 (2-3), 119-123. https://doi.org/10.1016/j.fcr.2009.03.009.

Boukar, O., Fatokun, C.A., Roberts, P.A., Abberton, M., Huynh, B.L., Close, T.J., Boahen, S., Higgins, T.J.V., Ehlers, J.D., 2015. Cowpea. In: In: De Ron, A. (Ed.), Grain Legumes. Handbook of Plant Breeding Vol 10. Springer, NY, pp. 219-250. https:// doi.org/10.1007/978-1-4939-2797-5_7.

Boukar, O., Fatokun, C.A., Huynh, B.L., Roberts, P.A., Close, T.J., 2016. Genomic tools in cowpea breeding programs: status and perspectives. Front. Plant Sci. 7, 757. https:// doi.org/10.3389/fpls.2016.00757.

Campos, P.S., Ramalho, J.C., Lauriano, J.A., Silva, M.J., Matos, M.C., 1999. Effects of drought on photosynthetic performance and water relations of four Vigna genotypes. Photosynthetica 36 (1), 79. https://doi.org/10.1023/a:1007018804086.

Carvalho, M., Lino-Neto, T., Rosa, E., Carnide, V., 2017. Cowpea: A legume crop for a challenging environment. J. Sci. Food Agric. 97 (13), 4273-4284. https://doi.org/10. 1002 jjsa.8250.

Chaves, M.M., Oliveira, M.M., 2004. Mechanisms underlying plant resilience to water deficits: Prospects for water-saving agriculture. J. Exp. Bot. 55 (407), 2365-2384. https://doi.org/10.1093/jxb/erh269.

Chaves, M.M., Maroco, J.P., Pereira, J.S., 2003. Understanding plant responses to drought - From genes to the whole plant. Funct. Plant Biol. 30 (3), 239-264. https://doi.org/ 10.1071/FP02076.

Chaves, M., Zarrouk, O., 2012. Crop responses to available soil water. In: Meyers, R.A. (Ed.), Encyclopedia of Sustainability Science and Technology. Springer-Verlag NY, pp. 2638-2661 ISBN 978-1-4419-0852-0.

Degenkolbe, T., Do, P.T., Kopka, J., Zuther, E., Hincha, D., Köhl, K., 2013. Identification of drought tolerance markers in a diverse population of rice cultivars by expression and metabolite profiling. PLoS ONE 8 (5), e63637. https://doi.org/10.1371/journal. pone.0063637.

Duvane, J.A., Jorge, T.F., Maquia, I., Ribeiro, N., Ribeiro-Barros, A.I., António, C., 2017. Characterization of the primary metabolome of Brachystegia boehmii and Colophospermum mopane under different fire regimes in Miombo and Mopane African woodlands. Front. Plant Sci. 8, 2130. https://doi.org/10.3389/fpls.2017.02130.

Fahad, S., Bajwa, A.A., Nazir, U., Anjum, S.A., Farooq, A., Zohaib, A., Sadia, S., Nasim, W., Adkins, S., Saud, S., Ihsan, M.Z., Alharby, H., Wu, C., Wang, D., Huang, J., 2017. Crop production under drought and heat stress: plant responses and management options. Front. Plant Sci. 8, 1147. https://doi.org/10.3389/fpls.2017.01147.

Fall, L., Diouf, D., Fall, A., Badiane, F.A., Gueye, M., 2003. Genetic diversity in cowpea [Vigna unguiculata (L.) Walp.] varieties determined by ARA and RAPD techniques. Afr. J. Biotechnol. 2 (2), 48-50. https://doi.org/10.5897/AJB2003.000-1009.

FAO - Food, Agriculture Organization of the United Nations, 2009. How to Feed the World in 2050. Synthesis Report. . https://www.fao.org/fileadmin/templates/wsfs/ docs/expert_paper/How_to_Feed_the_World_in_2050.pdf.

FAO - Food, Agriculture Organization of the United Nations, 2011. In: Conforti, P. (Ed.), Looking Ahead in World Food and Agriculture: Perspectives to 2050. FAO ISBN 97892-5-106903-5.

FAO - Food, Agriculture Organization of the United Nations, 2016. The State of Food and Agriculture - Climate Change, Agriculture and Food Security. FAO, Rome. Italy, pp. 24 ISBN 978-92-5-109374-0.

Flexas, J., Ribas-Carbó, M., Bota, J., Galmés, J., Henkle, M., Martínez-Cañellas, S., Medrano, H., 2006. Decreased rubisco activity during water stress is not induced by decreased relative water content but related to conditions of low stomatal conductance and chloroplast $\mathrm{CO}_{2}$ concentration. New Phytol. 172 (1), 73-82. https:// doi.org/10.1111/j.1469-8137.2006.01794.x.

Galmés, J., Aranjuelo, I., Medrano, H., Flexas, J., 2013. Variation in Rubisco content and activity under variable climatic factors. Photosynth. Res. 117, 73-90. https://doi. org/10.1007/s11120-013-9861-y.

Gill, S.S., Tuteja, N., 2010. Polyamines and abiotic stress tolerance in plants. Plant Signal. Behav. 5 (1), 26-33. https://doi.org/10.4161/psb.5.1.10291.

Gomes, A.M.F., Nhantumbo, N., Ferreira-Pinto, M., Massinga, R., Ramalho, J.C., RibeiroBarros, A., 2019. Breeding elite cowpea [Vigna unguiculata (L.) Walp] varieties for improved food security and income in Africa: opportunities and challenges. In: ElEsawi, M.A. (Ed.), Legume Crops. IntechOpen. https://doi.org/10.5772/intechopen. 84985.

Gonçalves, A., Goufo, P., Barros, A., Dominguez-Perles, R., Trindade, H., Rosa, E.A., Ferreira, L., Rodrigues, M., 2016. Cowpea (Vigna unguiculata L. Walp), a renewed multipurpose crop for a more sustainable agri-food system: Nutritional advantage and constraints. J. Sci. Food Agric. 96, 2941-2951. https://doi.org/10.1002/jsfa. 7644.

Goufo, P., Moutinho-Pereira, J.M., Jorge, T.F., Correia, C.M., Oliveira, M.R., Rosa, E.A.S., António, C., Trindade, H., 2017. Cowpea (Vigna Unguiculata L. Walp.) Metabolomics: Osmoprotection as a physiological strategy for drought stress resistance and improved yield. Front. Plant Sci. 8, 586. https://doi.org/10.3389/fpls.2017.00586.

Guo, R., Shi, L., Jiao, Y., Li, M., Zhong, X., Gu, F., Liu, Q., Xia, X., Li, H., 2018. Metabolic responses to drought stress in the tissues of drought-tolerant and drought-sensitive wheat genotype seedlings. AoB Plants 10 (2). https://doi.org/10.1093/aobpla/ ply016. ply016-ply016.

Hasan, M.M.-U., Ma, F., Prodhan, Z.H., Li, F., Shen, H., Chen, Y., Wang, X., 2018. Molecular and physio-biochemical characterization of cotton species for assessing drought stress tolerance. Int. J. Mol. Sci. 19https://doi.org/10.3390/ijms19092636. 2636.

Hayat, S., Hayat, Q., Nasser, M.A., Wani, A.S., Pichtel, J., Ahmad, A., 2012. Role of proline under changing environments: A review. Plant Signal. Behav. 7 (11), 1456-1466. https://doi.org/10.4161/psb.21949.

Hoekstra, F.A., Golovina, E.A., Buitink, J., 2001. Mechanisms of plant desiccation tolerance. Trends Plant Sci. 6 (9), 431-438. https://doi.org/10.1016/S1360-1385(01) 02052-0.

Huang, W., Zhang, S.-B., Cao, K.-F., 2011. Cyclic electron flow plays an important role in photoprotection of tropical trees illuminated at temporal chilling temperature. Plant Cell Physiol. 52 (2), 297-305. https://doi.org/10.1093/pcp/pcq166.

Huang, W., Yang, S., Zhang, S., Zhang, J., Cao, J., 2012. Cyclic electron flow plays an important role in photoprotection for the resurrection plant Paraboea rufescens under drought stress. Planta 235 (4), 819-828. https://doi.org/10.1007/s00425-011$1544-3$ 
IBPGR - International Board for Plant Genetic Resources, 1983. Descriptors for Cowpea, Vigna unguiculata (L.,) Walp. Vol. AGPG: IBPGR/82/80, June 1983. International Board for Plant Genetic Resources Secretariat Rome, Italy.

IFPRI - International Food Policy Research Institute, 2019. Global Food Policy Report. 2019. International Food Policy Research Institute, Washington, DC. https://doi.org/ 10.2499/9780896293502.

Iñiguez, C., Capó-Bauçà, S., Niinemets, Ü., Stoll, H., Aguiló-Nicolau, P., Galmés, J., 2020. Evolutionary trends in RuBisCO kinetics and their co-evolution with $\mathrm{CO}_{2}$ concentrating mechanisms. Plant J. 101, 897-918. https://doi.org/10.1111/tpj.14643.

Jorge, T., Duro, N., Costa, M., Florian, A., Ramalho, J.C., Ribeiro-Barros, A.I., Fernie, A., António, C., 2017. GC-TOF-MS analysis reveals salt stress-responsive primary metabolites in Casuarina glauca tissues. Metabolomics 13, 95. https://doi.org/10.1007/ s11306-017-1234-7.

Kalaji, H.M., Račková, L., Paganová, V., Swoczyna, T., Rusinowski, S., Sitko, K., 2018. Can chlorophyll-a fluorescence parameters be used as bio-indicators to distinguish between drought and salinity stress in Tilia cordata Mill? Environ. Exp. Bot. 152, 149-157. https://doi.org/10.1016/j.envexpbot.2017.11.001.

Karimzadeh-Soureshjani, H., Nezami, A., Kafi, M., Tadayon, M., 2019. Responses of two common bean (Phaseolus vulgaris L.) genotypes to deficit irrigation. Agric. Water Manag. 213, 270-279. https://doi.org/10.1016/j.agwat.2018.09.038.

Klughammer, C., Schreiber, U., 2008. Saturation pulse method for assessment of energy conversion in PS I. Heinz Walz GmbH 1, 11-14.

Kopka, J., Fernie, A., Weckwerth, W., Gibon, Y., Stitt, M., 2004. Metabolite profiling in plant biology: platforms and destinations. Genome Biol. 5 (6), 109. https://doi.org/ 10.1186/gb-2004-5-6-109.

Kramer, D.M., Johnson, G., Kiirats, O., Edwards, G., 2004. New fluorescence parameters for the determination of Qa redox state and excitation energy fluxes. Photosynth. Res. 79 (2), 209. https://doi.org/10.1023/B:PRES.0000015391.99477.0d.

Krause, G.H., Jahns, P., 2004. Non-photochemical energy dissipation determined by chlorophyll fluorescence quenching: characterization and function. In: In: Papageorgiou, G.C., Govindjee (Eds.), Chlorophyll a Fluorescence: A Signature of Photosynthesis. Chapter 18, Advances in Photosynthesis and Respiration Vol 19. Springer, Dordrecht, pp. 463-495. https://doi.org/10.1007/978-1-4020-3218-9_18.

Lamaoui, M., Jemo, M., Datla, R., Bekkaoui, F., 2018. Heat and drought stresses in crops and approaches for their mitigation. Front. Chem. 6, 26. https://doi.org/10.3389/ fchem.2018.00026.

Lauriano, J.A., Ramalho, J.C., Lidon, F.C., Matos, M.C., 2004. Peanut photosynthesis under drought and re-watering. Photosynthetica 42 (1), 37-41. https://doi.org/10 1023/B:PHOT.0000040567.42444.c2.

Li, Y., Li, H., Li, Y., Zhang, S., 2017. Improving water-use efficiency by decreasing stomatal conductance and transpiration rate to maintain higher ear photosynthetic rate in drought-resistant wheat. Crop J. 5 (3), 231-239. https://doi.org/10.1016/j.cj. 2017.01.001.

Lin, M.T., Occhialini, A., Andralojc, P.J., Parry, M.A., Hanson, M.R., 2014. A faster Rubisco with potential to increase photosynthesis in crops. Nature 513 (7519), 547-550. https://doi.org/10.1038/nature13776.

Lisec, J., Schauer, N., Kopka, J., Willmitzer, L., Fernie, A.R., 2006. Gas chromatography mass spectrometry-based metabolite profiling in plants. Nat. Protoc. 1, 387-396. https://doi.org/10.1038/nprot.2006.59.

Luedemann, A., Strassburg, K., Erban, A., Kopka, J., 2008. TagFinder for the quantitative analysis of gas chromatography-mass spectrometry (GC-MS)-based metabolite profiling experiments. Bioinformat. 24 (5), $732-737$ https://dx.doi.org/10.1093/ bioinformatics/btn023.

Marček, T., Hamow, K., Végh, B., Janda, T., Darko, E., 2019. Metabolic response to drought in six winter wheat genotypes. PLoS ONE 14 (2), e0212411. https://doi.org/ 10.1371/journal.pone.0212411.

Martins, M.Q., Rodrigues, W.P., Fortunato, A.S., Leitão, A.E., Rodrigues, A.P., Pais, I.P., Martins, L.D., Silva, M.G., Reboredo, F.H., Partelli, F.L., Campostrini, E., Tomaz, M.A., Scotti-Campos, P., Ribeiro-Barros, A.I., Lidon, F.J.C., DaMatta, F.M., Ramalho, J.C., 2016. Protective response mechanisms to heat stress in interaction with high $\left[\mathrm{CO}_{2}\right]$ conditions in Coffea spp. Front. Plant Sci. 7, 947. https://doi.org/10.3389/fpls. 2016.00947.

Mendelsohn, R., 2008. The impact of climate change on agriculture in developing countries. J. Nat. Resour. Policy Res. 1 (1), 5-19. https://doi.org/10.1080/ 19390450802495882.

Muller, B., Pantin, F., Génard, M., Turc, O., Freixes, S., Piques, M., Gibo, Y., 2011. Water deficits uncouple growth from photosynthesis, increase C content, and modify the relationships between C and growth in sink organs. J. Exp. Bot. 62, 1715-1729. https://doi.org/10.1093/jxb/erq438.

Müller, C., Cramer, W., Hare, W., Lotze-Campen, H., 2011. Climate change risks for African agriculture. Proc. Nat. Acad. Sci. USA 108 (11), 4313-4315. https://doi.org/ 10.1073/pnas.1015078108.

Mundim, F.M., Pringle, E.G., 2018. Whole-plant metabolic allocation under water stress. Front. Plant Sci. 9, 852. https://doi.org/10.3389/fpls.2018.00852.

Nagy, Z., Németh, E., Guóth, A., Bona, L., Wodala, B., Pécsváradi, A., 2013. Metabolic indicators of drought stress tolerance in wheat: Glutamine synthetase isoenzymes and Rubisco. Plant Physiol. Biochem. 67, 48-54. https://doi.org/10.1016/j.plaphy.2013. 03.001.

Obata, T., Witt, S., Lisec, J., Palacios-Rojas, N., Florez-Sarasa, I., Yousfi, S., Araus, J.L., Cairns, J.E., 2015. Metabolite profiles of maize leaves in drought, heat, and combined stress field trials reveal the relationship between metabolism and grain yield. Plant Physiol. 169, 2665-2683. https://doi.org/10.1104/pp.15.01164.

Osonubi, O., 1985. Responses of cowpeas (Vigna unguiculata (L.) Walp.) to progressive soil drought. Oecologia 66 (4), 554-557. https://doi.org/10.1007/BF00379349.

Pais, I.P., Reboredo, F.H., Ramalho, J.C., Pessoa, M.F., Lidon, F.C., Silva, M.M., 2020. Potential impacts of climate change on agriculture - A review. Emir. J. Food Agric accepted.

Parry, M.A., Andralojc, P.J., Scales, J.C., Salvucci, M.E., Carmo-Silva, A.E., Alonso, H., Whitney, S.M., 2013. Rubisco activity and regulation as targets for crop improvement. J. Exp. Bot. 64 (3), 717-730. https://doi.org/10.1093/jxb/ers336.

Pires, M.V., Pereira Jr., A.A., Medeiros, D.B., Daloso, D.M., Pham, A.P., Barros, K.A., Engqvist, M.K.M., Florian, A., Krahnert, I., Maurino, V.G., Araújo, W.L., Fernie, A.R., 2016. The influence of alternative pathways of respiration that utilize branched-chain amino acids following water shortage in Arabidopsis. Plant Cell Environ. 39 (6), 1304-1319. https://doi.org/10.1111/pce.12682.

R Core Team, 2016. R: A Language and Environment for Statistical Computing. R Foundation for Statistical Computing, Vienna, Austria. https://www.R-project.org/.

Ramalho, J.C., Chaves, M.M., 1992. Drought effects on plant water relations and carbon gain in two lines of Lupinus albus L. Eur. J. Agron. 1 (4), 271-280. https://doi.org/10. 1016/S1161-0301(14)80079-8.

Ramalho, J.C., Rodrigues, A.P., Semedo, J.N., Pais, I.P., Martins, L.D., Simões-Costa, M.C., Leitão, A.E., Fortunato, A.S., Batista-Santos, P., Palos, I.M., Tomaz, M.A., ScottiCampos, P., Lidon, F.C., DaMatta, F.M., 2013. Sustained photosynthetic performance of Coffea spp. under long-term enhanced $\left[\mathrm{CO}_{2}\right]$. PLoS ONE 8 (12), e82712. https:// doi.org/10.1371/journal.pone.0082712.

Ramalho, J.C., Zlatev, Z.S., Leitão, A.E., Pais, I.P., Fortunato, A.S., Lidon, F.C., 2014. Moderate water stress causes different stomatal and non-stomatal changes in the photosynthetic functioning of Phaseolus vulgaris L. genotypes. Plant Biol. 16 (1), 133-146. https://doi.org/10.1111/plb.12018.

Ramalho, J.C., Rodrigues, A.P., Lidon, F.C., Marques, L.C., Leitão, A.E., Fortunato, A.S., Pais, I.P., Silva, M.J., Scotti-Campos, P., Lopes, A., Reboredo, F.H., Ribeiro-Barros, A.I., 2018. Stress cross-response of the antioxidative system promoted by superimposed drought and cold conditions in Coffea spp. PLoS ONE 13 (6), e0198694. https://doi.org/10.1371/journal.pone.0198694.

Reddy, A.R., Chaitanya, K.V., Vivekanandan, M., 2004. Drought-induced responses of photosynthesis and antioxidant metabolism in higher plants. J. Plant Physiol. 161 1189-1202. https://doi.org/10.1016/j.jplph.2004.01.013.

Rejšková, A., Patková, L., Stodůulková, E., Lipavská, H., 2007. The effect of abiotic stresses on carbohydrate status of olive shoots (Olea europaea L.) under in vitro conditions. J. Plant Physiol. 164, 174-184. https://doi.org/10.1016/j.jplph.2005.09. 011.

Rodrigues, W.P., Martins, M.Q., Fortunato, A.S., Rodrigues, A.P., Semedo, J.N., SimõesCosta, M.C., Pais, I.P., Leitão, A.E., Colwell, F., Goulao, L., Máguas, C., Maia, R., Partelli, F.L., Campostrini, E., Scotti-Campos, P., Ribeiro-Barros, A.I., Lidon, F.C., DaMatta, F.M., Ramalho, J.C., 2016. Long-term elevated air $\left[\mathrm{CO}_{2}\right]$ strengthens photosynthetic functioning and mitigates the impact of supra-optimal temperatures in tropical Coffea arabica and C. canephora species. Global Change Biol. 22 (1), 415-431. https://doi.org/10.1111/gcb.13088.

Rohart, F., Gautier, B., Singh, A., Cao, L.ê, 2017. mixOmics: an R package for `omics feature selection and multiple data integration. PLoS Comput. Biol. 13 (11), e1005752. https://doi.org/10.1371/journal.pcbi.1005752.

Rosales, M.A., Ocampo, E., Rodríguez-Valentín, R., Olvera-Carrillo, Y., Acosta-Gallegos, J., Covarrubias, A., 2012. Physiological analysis of common bean (Phaseolus vulgaris L.) cultivars uncovers characteristics related to terminal drought resistance. Plant Physiol. Biochem. 56, 24-34. https://doi.org/10.1016/j.plaphy.2012.04.007.

Rosales, M.A., Cuellar-Ortiz, S., Arrieta-Montiel, M., Acosta-Gallegos, J., Covarrubias, A., 2013. Physiological traits related to terminal drought resistance in common bean (Phaseolus vulgaris L.). J. Sci. Food Agric. 93 (2), 324-331. https://doi.org/10.1002/ jsfa.5761.

Sanchez, D.H., Schwabe, F., Erban, A., Udvardi, K., Kopka, J., 2012. Comparative metabolomics of drought acclimation in model and forage legumes. Plant Cell Environ. 35 (1), 136-149. https://doi.org/10.1111/j.1365-3040.2011.02423.x.

Santarius, K.A., 1973. The protective effect of sugars on chloroplast membranes during temperature and water stress and its relationship to frost, desiccation and heat resistance. Planta 113, 105-114. https://doi.org/10.1007/BF00388196.

Schauer, N., Steinhauser, D., Strelkov, S., Schomburg, D., Allison, G., Moritz, T., Lundgren, K., Roessner-Tunali, U., Forbes, M.G., Willmitzer, L., Fernie, A.R., Kopka, J., 2005. GC-MS libraries for the rapid identification of metabolites in complex biological samples. FEBS Lett. 579 (6), 1332-1337. https://doi.org/10.1016/j.febslet. 2005.01.029.

Schreiber, U., 2004. Pulse-amplitude-modulation (PAM) fluorometry and saturation pulse method: an overview. In: In: Papageorgiou, G.C., Govindjee (Eds.), Chlorophyll a Fluorescence: A Signature of Photosynthesis. Chapter 11, Advances in Photosynthesis and Respiration 19. Springer, Dordrecht, pp. 279-319. https://doi.org/10.1007/9781-4020-3218-9_11.

Scotti-Campos, P., Pham-Thi, A.-T., Semedo, J., Pais, I., Ramalho, J.C., Matos, M.C., 2013. Physiological responses and membrane integrity in three Vigna genotypes with contrasting drought tolerance. Emir. J. Food Agri. 25 (12), 1002-1013. https://doi.org/ 10.9755/ejfa.v25i12.16733.

Singh, S.K., Reddy, K.R., 2011. Regulation of photosynthesis, fluorescence, stomatal conductance and water-use efficiency of cowpea (Vigna unguiculata [L.] Walp.) under drought. J. Photochem. Photobiol. B 105 (1), 40-50. https://doi.org/10.1016/j. jphotobiol.2011.07.001.

Stirbet, A., Govindjee, 2011. On the relation between the kautsky effect (chlorophyll a fluorescence induction) and photosystem II: Basics and applications of the OJIP fluorescence transient. J. Photochem. Photobiol. B. 104 (1), 236-257. https://doi. org/10.1016/j.jphotobiol.2010.12.010.

Tezara, W., Mitchell, V., Driscoll, S.P., Lawlor, D.W., 2002. Effects of water deficit and its interaction with $\mathrm{CO}_{2}$ supply on the biochemistry and physiology of photosynthesis in sunflower. J. Exp. Bot. 53 (375), 1781-1791. https://doi.org/10.1093/jxb/erf021.

Tian, H., Lam, S.M., Shui, G., 2016a. Metabolomics, a powerful tool for agricultural research. Int. J. Mol. Sci. 17 (11), 1871. https://doi.org/10.3390/ijms17111871. 
Tian, J., Brian, C.B., Rickey, Y.Y., 2016b. Feeding the world into the future - food and nutrition security: The role of food science and technology. Front Life Sci. 9 (3), 155-166. https://doi.org/10.1080/21553769.2016.1174958.

Ullah, N., Yüce, M., Gökçe, Z.N.Ö., Budak, H., 2017. Comparative metabolite profiling of drought stress in roots and leaves of seven Triticeae species. BMC Gen. 18, 969. https://doi.org/10.1186/s12864-017-4321-2.

UN - United Nations, 2019. World Population Prospects 2019: Highlights. https:// population.un.org/wpp/Publications/Files/WPP2019_10KeyFindings.pdf.

Vu, J.C.V., Gesch, R.W., Allen, L.H., Boote, K.J., Bowes, G., 1999. $\mathrm{CO}_{2}$ enrichment delays a rapid, drought-induced decrease in Rubisco small subunit transcript abundance. J. Plant Physiol. 155, 139-142. https://doi.org/10.1016/S0176-1617(99)80156-4.

Wang, X., Cai, X., Xu, C., Wang, Q., Dai, S., 2016. Drought-responsive mechanisms in plant leaves revealed by proteomics. Int. J. Mol. Sci. 17 (10), 1706. https://doi.org/ 10.3390/ijms17101706.

Werner, C.M., Correia, O., Beyschlag, W., 2002. Characteristic patterns of chronic and dynamic photoinhibition of different functional groups in a mediterranean ecosystem. Funct. Plant Biol. 29, 999-1011. https://doi.org/10.1071/PP01143.

White, A.J., Critchley, C., 1999. Rapid light curves: A new fluorescence method to assess the state of the photosynthetic apparatus. Photosynth. Res. 59 (1), 63-72. https:// doi.org/10.1023/a:1006188004189.

Winter, G., Todd, C.D., Trovato, M., Forlani, G., Funck, D., 2015. Physiological implications of arginine metabolism in plants. Front. Plant Sci. 6, 534. https://doi.org/10 3389/fpls.2015.00534.

Wu, H., Fu, B., Sun, P., Xiao, C., Liu, J., 2016. A NAC transcription factor represses putrescine biosynthesis and affects drought tolerance. Plant Physiol. 172 (3), 1532-1547. https://doi.org/10.1104/pp.16.01096.

Yadav, A.K., Carroll, A.J., Estavillo, G.M., Rebetzke, G.J., Pogson, B.J., 2019. Whea drought tolerance in the field is predicted by amino acid responses to glasshouseimposed drought. J. Exp. Bot. 70 (18), 4931-4948. https://doi.org/10.1093/jxb/ erz224.

Yang, J., Zhang, J., Liu, K., Wang, Z., Liu, L., 2007. Involvement of polyamines in the drought resistance of rice. J. Exp. Bot. 58 (6), 1545-1555. https://doi.org/10.1093/ jxb/erm032.

You, J., Zhang, Y., Liu, A., Li, D., Wang, X., Dossa, K., 2019. Transcriptomic and metabolomic profiling of drought-tolerant and susceptible sesame genotypes in response to drought stress. BMC Plant Biol. 19 (1), 267. https://doi.org/10.1186/s12870-0191880-1.

Zegaoui, Z., Planchais, S., Cabassa, C., Djebbar, R., Abrousbelbachir, O., Carol, P., 2017. Variation in relative water content, proline accumulation and stress gene expression in two cowpea landraces under drought. J. Plant Physiol. 218, 26-34. https://doi. org/10.1016/j.jplph.2017.07.009.

Zeid, I.M., Shedeed, Z.A., 2006. Response of alfalfa to putrescine treatment under drought stress. Biol. Plant. 50 (4), 635. https://doi.org/10.1007/s10535-006-0099-9. 